University of Wollongong

Research Online

Faculty of Engineering and Information

Faculty of Engineering and Information

Sciences - Papers: Part B

Sciences

2018

Study of reaction sequences during MSR synthesis of TiC by controlled ball milling of titanium and graphite

Erhuvwu J. Oghenevweta

University of Wollongong, ejo766@uowmail.edu.au

David Wexler

University of Wollongong, davidw@uow.edu.au

Andrzej Calka

University of Wollongong, acalka@uow.edu.au

Follow this and additional works at: https://ro.uow.edu.au/eispapers1

Part of the Engineering Commons, and the Science and Technology Studies Commons

Research Online is the open access institutional repository for the University of Wollongong. For further information contact the UOW Library: research-pubs@uow.edu.au 


\title{
Study of reaction sequences during MSR synthesis of TiC by controlled ball milling of titanium and graphite
}

\begin{abstract}
During reactive ball milling of $\mathrm{Ti}$ and $\mathrm{C}$, mechanically induced self-propagating reaction (MSR) synthesis of $\mathrm{TiC}$ is reported to occur via a process including initial formation of small amounts of TiC prior to exothermic ignition, followed by MSR and the formation of stiochiometric TiC (Dorofeev et al., 2011; Oghenevweta et al., 2016 [1, 2]). However, both the chemical evolution and mechanisms of reaction and growth of TiC both prior to, during and after ignition are not fully understood. This research focuses on fundamental understanding of the reaction sequences during MSR synthesis of TiC from elemental Ti and C (graphite).

Magnetically controlled ball milling of stoichiometric (1:1) powder mixtures of titanium (Ti) and graphite (C) was performed under He gas with the exothermic ignition point by determined via in-situ temperature measurement. X-ray diffraction, Scanning Transmission Electron Microscopy (STEM) with electron energy loss spectroscopy (EELS), Raman Spectroscopy and X-ray Photoelectron Spectroscopy (XPS) were employed to interpret the reaction sequences.

The reaction sequence involved the following: During milling prior to ignition, severely deformed $\mathrm{Ti}$, spheriodised graphite and amorphous carbon forms, and minor amounts of off-stiochiometric nano$\mathrm{TiC}_{1-\mathrm{x}}$ crystals. In addition to the formation of $\mathrm{TiC}_{1-\mathrm{x}}$, XPS revealed the formation of oxide skins coating the surface regions of the milled powders. There is also an evolution towards stiochiometric TiC with increasing milling time. Immediately after ignition, a reacted product comprising a mixture of multi-layer stacks of thin TiC plates form, in addition to a matrix comprising large TiC particles which have been liquid phase sintered under the high local heat of reaction by thin layers of unreacted Ti. MSR occurs via a dual mechanism involving rapid growth of existing TiC, plus nucleation and growth of new TiC. High spatially resolved EELS combined with STEM revealed additional information about the inhomogeneous chemical environment of the milled powders.
\end{abstract}

\section{Keywords}

ball, controlled, tic, synthesis, msr, during, study, reaction, sequences, milling, titanium, graphite

\section{Disciplines}

Engineering | Science and Technology Studies

\section{Publication Details}

Oghenevweta, J. E., Wexler, D. \& Calka, A. (2018). Study of reaction sequences during MSR synthesis of TiC by controlled ball milling of titanium and graphite. Materials Characterization, 140 299-311. 


\title{
Study of reaction sequences during MSR synthesis of TiC by controlled ball milling of titanium and graphite
}

\author{
J.E. Oghenevweta ${ }^{a},{ }^{b, *}$, D. Wexler ${ }^{b}$, A. Calka ${ }^{b}$ \\ a Department of Metallurgical and Materials Engineering, Faculty of Engineering, Ahmadu \\ Bello University, Nigeria \\ ${ }^{\mathrm{b}}$ Faculty of Engineering and Information Sciences, University of Wollongong, Australia \\ Corresponding author at: Faculty of Engineering and Information Sciences, University of \\ Wollongong, Northfields Avenue, Wollongong, New South Wales 2522, Australia. \\ E-mail addresses: ejo766@uowmail.edu.au, joghenevweta@abu.edu.ng (J.E. \\ Oghenevweta).
}

\section{ABSTRACT}

During reactive ball milling of $\mathrm{Ti}$ and $\mathrm{C}$, mechanically induced self-propagating reaction (MSR) synthesis of TiC is reported to occur via a process including initial formation of small amounts of TiC prior to exothermic ignition, followed by MSR and the formation of stiochiometric TiC (Dorofeev et al., 2011; Oghenevweta et al., 2016 [1, 2]). However, both the chemical evolution and mechanisms of reaction and growth of TiC both prior to, during and after ignition are not fully understood. This research focuses on fundamental understanding of the reaction sequences during MSR synthesis of TiC from elemental Ti and C (graphite).

Magnetically controlled ball milling of stoichiometric (1:1) powder mixtures of titanium(Ti) and graphite (C) was performed under $\mathrm{He}$ gas with the exothermic ignition point by determined via in-situ temperature measurement. X-ray diffraction, Scanning Transmission Electron Microscopy (STEM) with electron energy loss spectroscopy (EELS), Raman Spectroscopy and X-ray Photoelectron Spectroscopy (XPS) were employed to interpret the reaction sequences.

The reaction sequence involved the following: During milling prior to ignition, severely deformed Ti, spheriodised graphite and amorphous carbon forms, and minor amounts of offstiochiometric nano- $\mathrm{TiC}_{1-\mathrm{x}}$ crystals. In addition to the formation of $\mathrm{TiC}_{1-\mathrm{x}}$, XPS revealed the formation of oxide skins coating the surface regions of the milled powders. There is also an evolution towards stiochiometric $\mathrm{TiC}$ with increasing milling time. Immediately after ignition, a reacted product comprising a mixture of multi-layer stacks of thin TiC plates form, in addition to a matrix comprising large TiC particles which have been liquid phase sintered under the high local heat of reaction by thin layers of unreacted Ti. MSR occurs via a dual mechanism involving rapid growth of existing TiC, plus nucleation and growth of new TiC. High spatially resolved EELS combined with STEM revealed additional information about the inhomogeneous chemical environment of the milled powders.

Keywords

Mechanically induced self-propagating reaction, TiC formation, STEM, EELS, XPS, Raman spectroscopy 


\section{Introduction}

Nanoparticles containing $\mathrm{TiC}$ have been used in precursor powders for the production of cutting tools, coatings for heat shields and wear-resistant tools and ceramicmetalcomposites [3,4]. Production of precursor titanium carbide (TiC) powder via mechanically induced combustion reaction between elemental powder mixtures of titanium and graphite ingredients is well reported and published in several papers [4-9]. The route, often known as mechanically induced self-propagating reaction (MSR), is performed via high energy ball milling of the elemental ingredients until a sudden exothermic reaction occurs at a point known as the ignition point. Before the ignition point, the softer titanium particles are plastically deformed to generate high accumulations of strains and defects, while the graphitic particles simply break up, and align along the nano-titanium grains $[1, \underline{10}]$. After

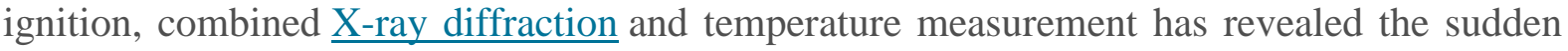
formation of TiC, as reported in several works $[7, \underline{11}, \underline{12}]$. However, gradually formation of TiC without detection of an ignition peak (often known as mechanically induced solid-state diffusion reaction (MDR) or mutual suppression of ignition (MSI)) has equally been reported $[4,8]$. Typically, whether the reaction will progress by MSR or MDR depends on the milling conditions $[\underline{3}, \underline{4}, \underline{13}]$.

The reaction mechanisms operative in the MSR synthesis of $\mathrm{TiC}$ have been reported in different investigations to be very complex $[4-6,14]$, due to the several milling conditions that affect the processes. The formation mechanism of TiC via MSR is believed to occur in the three-step process of milling: incubation (pre-ignition), ignition and post-ignition. The observed reaction kinetics involved in the high energy ball milling of elemental powder mixtures has previously been explained using considerations including those based on: thermodynamic [15, 16], collision energy and frequency [17], numerical [1] $]$ and statistical [20], macrokinetic modelling [199], and others [21,22]. However, none of these presented so far have been able to explain the kinetics of MSR.

Mechanically induced self-propagating reaction of titanium and graphite in atomic composition of $\mathrm{Ti}_{50} \mathrm{C}_{50}$ was found to results in the rapid formation of $\mathrm{TiC}$ phase at the ignition point $[4,7, \underline{8}, \underline{10}, \underline{23}, \underline{24}]$. More recently, techniques of Raman spectroscopy[2,25] and X-ray photoelectron spectroscopy (XPS) $[\underline{1}, 2,7]$ demonstrated that important structural changes occur during the incubation period prior to ignition. In these investigations, detailed evidence for formation of titanium carbide prior to the ignition point was presented [1,2] however, there was no direct evidence of the carbide morphology, and discussion as to whether the TiC, occurs as crystalline [2], and/or in the amorphous state (amTiC) [1]. In our recent short publication [2], high resolution transmission electron microscopy (HRTEM) combined with selected area electron diffraction technique (SAD) revealed that the prior TiC crystals are located within the vicinity of the interface of the amorphous $\mathrm{C}$ and nanocrystalline $\mathrm{Ti}$ and after ignition, rapid growth of pre-existing nuclei and the nucleation and growth of additional off-stoichiometric $\mathrm{Ti}_{(1+\mathrm{x})} \mathrm{C}_{(1-\mathrm{x})}$ occurs. Interestingly, in a similar study involving mechanically induced self-propagating reactions of $\mathrm{Ti}$ and $\mathrm{B}$ to form $\mathrm{TiB}$ and $\mathrm{TiB}_{2}$ [26], off-stoichiometric $\mathrm{TiB}_{2-\mathrm{x}}$ was detected prior to ignition, based on HRTEM evidence, appearing to nucleate on highly deformed Ti particles and grow into a surrounding nanostructure of Ti and B [26].

In the current research, we use advanced techniques of aberration corrected scanning TEM (STEM) combined with spatially-resolved electron energy loss spectroscopy (EELS) and additional Raman Spectroscopy and XPS to obtain more fundamental understanding of the formation of off-stoichiometric $\mathrm{TiC}_{1-\mathrm{x}}$ phase prior to ignition particularly, the transitions from off-stoichiometric to near-stoichiometric TiC, the formation of oxide skins, and mechanism of the growth of the TiC after ignition. Spatially-resolved EELS enables 
quantification of off-stoichiometric $\mathrm{TiC}_{1-\mathrm{x}}$ formation as a function of milling time, allowing us to infer more concerning the reaction between Ti and graphite. Additional X-ray Rietveld refinement work is also presented to determine local crystallite size and strain effects.

\section{Materials and Experimental Procedure}

Ball milling of elemental powder mixtures of titanium (Ti) (Sigma Aldrich ${ }^{\circledR}, 99.9 \%$ purity, $\leq 250 \mu \mathrm{m}$ ) and graphite (C) (Sigma Aldrich ${ }^{\circledR}, 99.9 \%$ purity, $\leq 20 \mu \mathrm{m}$ ) with an atomic composition of $\mathrm{Ti}_{50} \mathrm{C}_{50}$ was performed in a magnetically controlled ball mill under Helium atmosphere, ball to powder ratio (BPR) of 27:1 and milling chamber temperature measured using an external pyrometer [2]. Milling was interrupted at different milling times and small aliquots of milled products were taken out for characterization. $\underline{X-r a y}$ diffraction (XRD) was performed using a GBC diffractometer with $\mathrm{Cu} \mathrm{K}_{\alpha}$ radiation, graphite monochromator and Traces ${ }^{\mathrm{TM}}$ software and the PC-PDF database used to analyse diffractometer output. The XRD patterns were also analysed using the Rietveld method analysis software, Materials Analysis Using Diffraction (MAUD), to estimate the crystallite sizes, lattice parameters and lattice strains of the milled products. The MAUD software is typically designed as a refinement method where more accurate microstructural parameters are to be obtained [27-29]. This method uses a non-linear least squares algorithm (Marquardt least-squares), as described by Ghosh et al. [24]. The XRD profiles were initially fitted with pseudo-Voigt (pV), Gaussian $(\mathrm{G})$ and Lorentzian (L) functions parameters until the quality factor (GOF) is very close to unity. However, fitting using the pseudo-Voigt (pV) function typical gave the most reliable refinement, as the good fitness factor converges more readily between 1.2 and 1.5 [24]. Results of the quantitative analyses were extracted after sufficient convergence was obtained [30].

Field emission scanning electron microscopy (FESEM) was performed using JEOL JSM7001F Schottky field emission gun-scanning electron microscopy (FEG-SEM) equipped with a $80 \mathrm{~mm}^{2} \mathrm{X}-\mathrm{Max}^{\mathrm{N}}$ energy dispersive X-ray spectroscopy (EDS) silicon drift detector. TEM images were acquired using a $200 \mathrm{kV}$ JEOL JEM-2011 analytical TEM (imaging resolution $0.16 \mathrm{~nm}$ ) equipped with a $\mathrm{LaB}_{6}$ electron source, Gatan Orius CCD camera and a JEOL SiLi energy dispersive $\mathrm{x}$-ray detector (EDS). High resolution images were acquired using a probecorrected JEOL ARM-200F TEM/STEM (110 pm resolution) and STEM (78 pm), equipped with a cold field emission gun source, Gatan UltraScan 1000XP CCD camera $(2 \mathrm{k} \times 2 \mathrm{k})$ and a JEOL $100 \mathrm{~mm}^{2}$ SDD EDS detector and a GIF Quantum image filter electron energy loss spectrometer (EELS).

The STEM-EELS experiments were performed using a convergence semi-angle $\alpha$ of $\sim 24.5 \mathrm{mrad}$ and a collection semi angle $\beta$ of $\sim 8.0 \mathrm{mrad}$, using a beam current of approximately $80 \mathrm{pA}$. While, the high angle annular dark-field (HAADF-STEM) imaging was carried out with an inner collection semi-angle of $\sim 80 \mathrm{mrad}$ and an outer collection semiangle of $160 \mathrm{mrad}$. All spectra were acquired at an energy dispersion of $0.1 \mathrm{eV}$ per channel (pixel) and an energy resolution of approximately $1.2 \mathrm{eV}$. The $\mathrm{C} \mathrm{K}$ - and $\mathrm{Ti} \mathrm{L}_{2,3}$-edges spectra were processed using the SITools plugin in the Gatan DigitalMicrograph software [31]. Processing involved subtracting the background modelled using a standard power-law function. EELS edge intensities were converted into compositions using the quantification routines and scattering cross sections built into the DigitalMicrograph software.

Additional chemical composition and bonding investigations were performed using laser micro-Raman spectroscopy and X-ray photoelectron spectroscopy (XPS). Raman spectroscopy was conducted using a John Yvon HR800 HeNe $632.81 \mathrm{~nm}$ laser line equipped with a thermoelectrically cooled $\left(-70^{\circ} \mathrm{C}\right) \mathrm{CCD}$ detector and a long working distance (LWD) confocal $\times 50$ objective lens. During spectra acquisition, a notch-type optical laser blocking filter was inserted to block the highly intense laser beam from possible surface contamination 
while maintaining the acquisition time for each spectrum at $50 \times 5 \mathrm{~s}$ while the acquired Raman spectra were analysed using LabSpec 5 software. The XPS was conducted using a SPECS PHOIBOS 100 Analyser installed in a high-vacuum chamber with the base pressure below $10^{-8}$ mbar. X-ray excitation was provided by $\mathrm{Al} \mathrm{K} \alpha$ radiation with photon energy $\mathrm{h} v=1486.6 \mathrm{eV}$ at the high voltage of $12 \mathrm{kV}$ and power of $120 \mathrm{~W}$. The XPS binding energy spectra were recorded at the pass energies of $20 \mathrm{eV}$ and step width of $0.05-0.3 \mathrm{eV}$ in the fixed analyser transmission mode. Analysis of the XPS data was carried out by using the commercial CasaXPS2.3.15 software package.

\section{Results}

\subsection{External Temperature Measurement of the Milling Vial}

Temperature measurements obtained from the outside of the milling vial during controlled ball milling of $\mathrm{Ti}_{50} \mathrm{C}_{50}$ revealed three distinct stages that can be identified: incubation, ignition and post-ignition (Fig. 1). The incubation stage is associated with an initial increase in the temperature of the vial which then stabilizes unto a steady-state, consistent with several workers $[\underline{3}, \underline{4}, \underline{6}, \underline{13}]$.

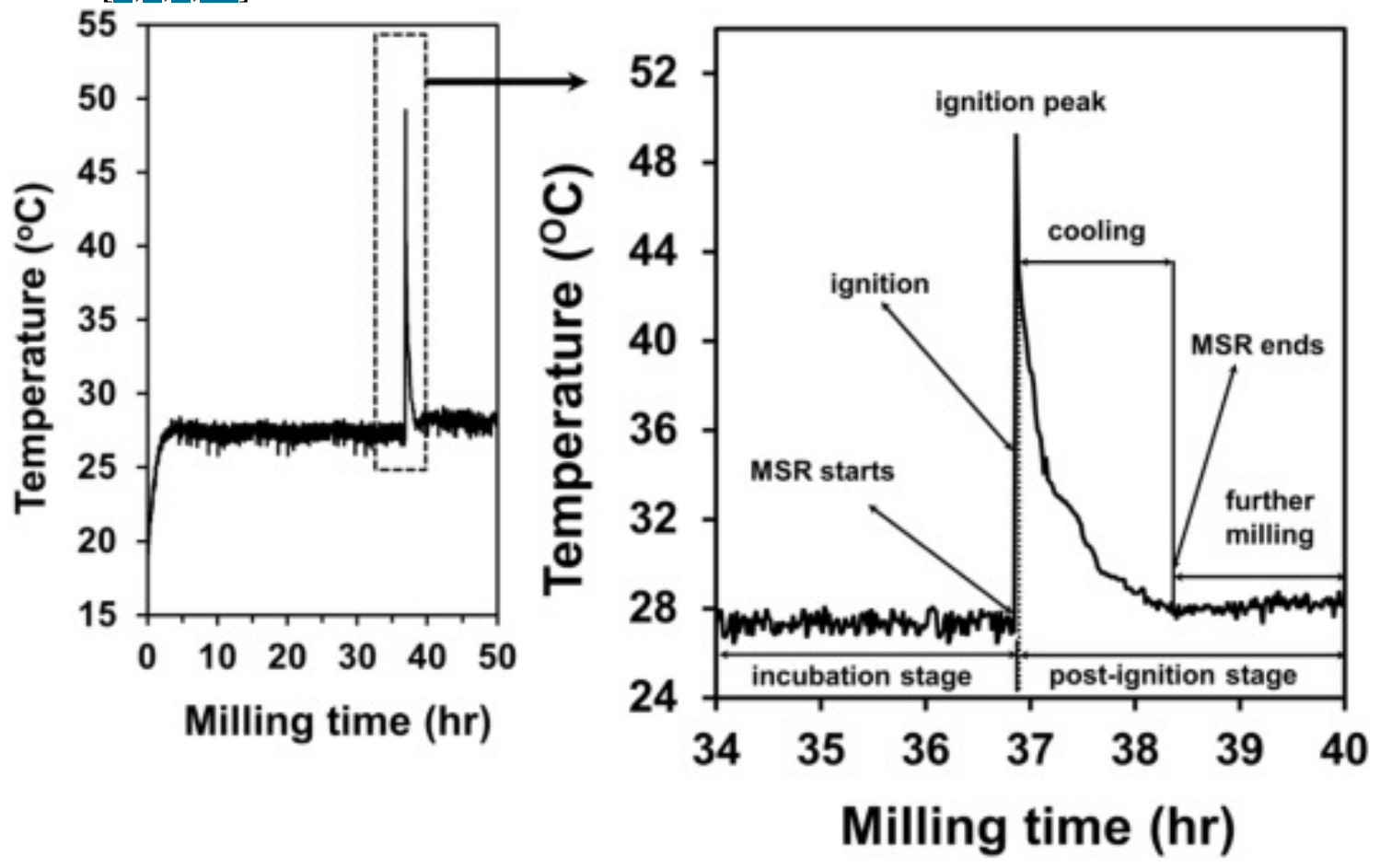

Fig.1. Plots of external temperature of the vial vs milling time during magnetically controlled ball milling of $\mathrm{Ti}_{50} \mathrm{C}_{50}$ mixture

The initial increase in the temperature of the vial is attributed to heat generation due to repeated ball-to-ball or ball-to-wall collision. With increase milling time there was sudden temperature rise, detected as sharp peak which corresponds to an ignition (stage two). This was accompanied by a characteristic change in the sound of the ball motion and the mill, which occurred within a short period of time. Thereafter (post-ignition stage), cooling of the vial commences during which time the heat released due to reaction between $\mathrm{Ti}$ and $\mathrm{C}$ is presumably dissipates into the mill and surroundings until the temperature decreases back to the previous steady-state duration. The duration of cooling was characteristically long (within $2-3 \mathrm{~h}$ ), which is not observed in most MSR investigations $[\underline{4}, \underline{13}, \underline{15}]$. This may be attributed to relatively slow heat dissipation into the stainless steel vial and steel balls. The cooling part 
of the temperature-time curve appears erratic, with evidence of rise and fall in the temperature of the vial. Such behaviour may indicate either further spontaneous reaction of unreacted local products of $\mathrm{Ti}$ and $\mathrm{C}$ or irregular cooling associated with the poor thermal conductivity of the stainless steel vial.

\subsection{X-Ray Diffraction Analysis}

Fig. 2 shows XRD patterns obtained for $\mathrm{Ti}_{50} \mathrm{C}_{50}$ mixtures at different milling times. The graphite peaks disappeared after $10 \mathrm{~h}$ of milling while the Ti peaks slightly broadened and continuously shifted to lower Bragg angles, particularly after milling for $5 \mathrm{~h}$ (Fig. $2(5 \mathrm{~h})$. Notably, the relative intensities of the (002) Ti peaks over other peaks appear to have increased after milling for 5 and $10 \mathrm{~h}$, a result attributable to texture evolution during the initial stages of deformation. There was no XRD evidence of TiC formation prior to ignition, consistent with $[\underline{4}, \underline{6}, \underline{23}, \underline{32}]$. Immediately after ignition, the XRD pattern (Fig. 2 (37 h)) shows a very sharp peak indexed with PDF card \# 32-1383 (space group, Fm-3m (225), lattice parameter, $\mathrm{a}_{0}=4.3274 \AA$ ) that matches face-centred cubic of NaCl-type crystal structure of TiC. Additional weak and broad peaks that match unreacted Ti were also detected in the XRD pattern, suggesting incomplete reaction obtained immediately after ignition. With further milling times up to 55 and $75 \mathrm{~h}$, the TiC peaks became significantly reduced and broadened, likely indicating the formation of nanostructural grains of TiC.

Using Rietveld microstructural refinement, the estimated Ti crystallite sizes were found to decrease with milling time, a result attributed to the repeated action of collision ball impacts on the reacting particles resulting to size reduction. The lattice strainincreased monotonically (Table 1) and this is attributed to accumulation of deformation defects induced in the Ti particles. A slight increase in the lattice parameter is likely associated with: (1) formation of a solid solution of $\mathrm{C}$ in $\mathrm{Ti}(\alpha \mathrm{Ti})$; (2) introduction of internal strain, resulting to small anisotropic expansion of the unit cell; and (3) the high likelihood of formation of "unpaired electronic orbitals at the outer surface of each metallic particle". Such surface array of electron dipoles could repel each other resulting to larger lattice parameter than the bulk material, consistent with [33, $\underline{34}]$.

While the slight decrease in the lattice parameter of titanium obtained just prior to ignition (36 h of milling) may probably be due to effects associated with accumulated defects on the surfaces of titanium nanoparticles [33, $\underline{34}$ ]. As earlier explained by Shenoy et al. [35] and Modi et al. [33], the presence of high accumulated defects present in the nanoparticles could cause both the surface energy and the surface tension of nanoparticles to be very high and this could shrink the Ti lattice parameter [35]. Immediately after ignition, the lattice parameter estimated for TiC $(\mathrm{a}=4.3163 \AA)$ increases with further milling times $(\mathrm{a}=4.3163 \AA$ at $47 \mathrm{~h}$ and $\mathrm{a}=4.3186 \AA$ at $55 \mathrm{~h}$ ), indicating an evolution of TiC towards stoichiometry. The TiC crystallite size decreases with increasing milling time while there is a continuous increase in TiC lattice strain of TiC (Table 1). 


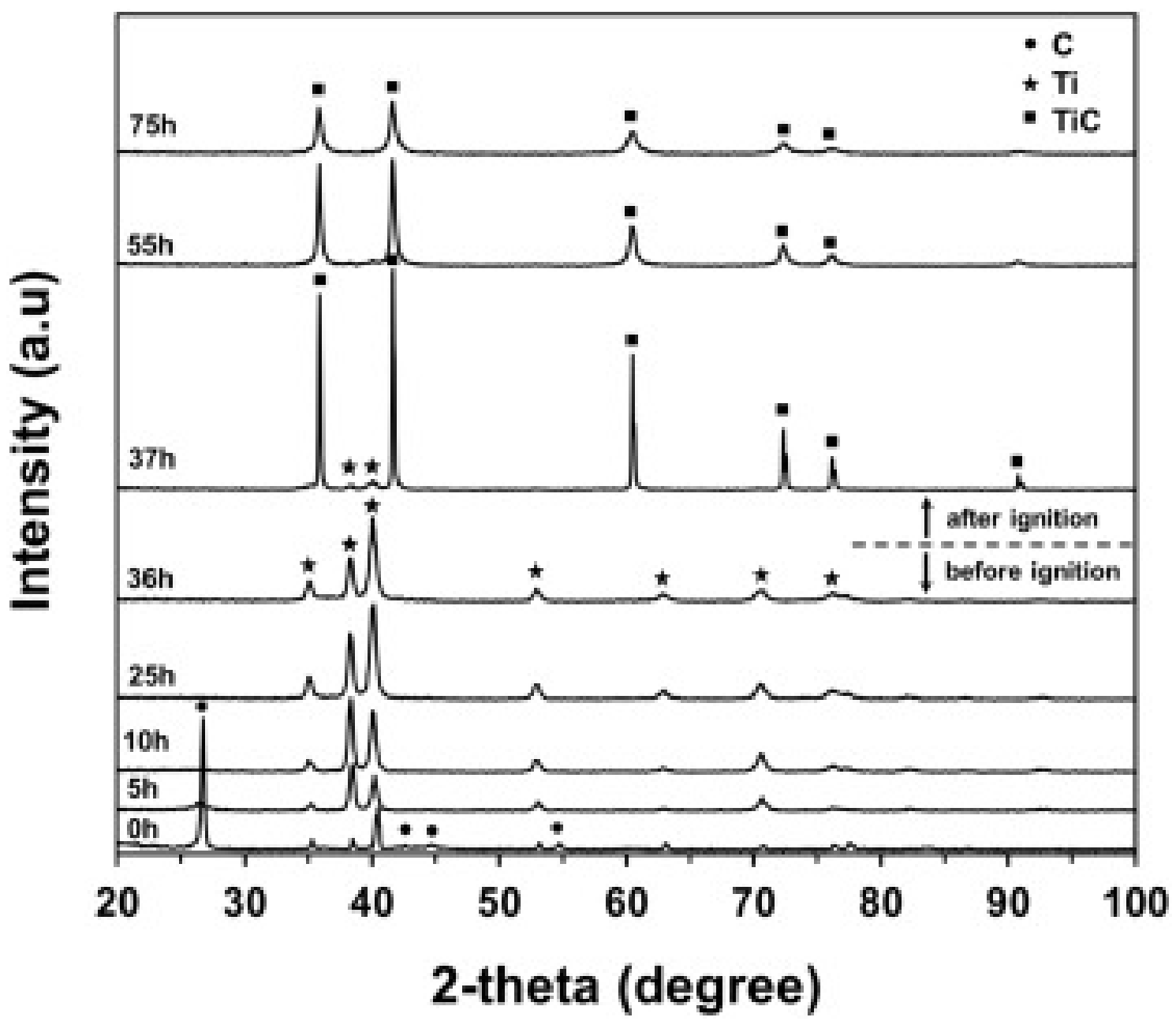

Fig.2. XRD patterns obtained for $\mathrm{Ti}_{50} \mathrm{C}_{50}$ mixture, sampled at different milling times [2]

Table1. Estimation of lattice parameters, lattice strain and crystallite sizes or $\mathrm{Ti}$ and $\mathrm{TiC}$ with increasing milling times using Rietveld method of analysis.

Milling time (h) Phase present Lattice parameter $(\AA)$ Lattice strain $\left(\times 10^{-3}\right) \quad$ Crystallite sizes $(\mathrm{nm})$

a c

$\mathrm{Ti}$

$2.9490 \quad 4.6792 \quad-$

145

0

C

2.4547

6.6908

118

$\mathrm{Ti}$

2.9491

4.6794

1.89

32

5

C

2.4625

6.7121

4

10

$\mathrm{Ti}$

2.9510

4.6824

2.04

30 


\section{Milling time (h) Phase present Lattice parameter (Å) Lattice strain $\left(\times 10^{-3}\right)$ Crystallite sizes (nm)}

\begin{tabular}{|c|c|c|c|c|c|}
\hline 25 & $\mathrm{Ti}$ & 2.9521 & 4.6842 & 2.14 & 20 \\
\hline 36 & $\mathrm{Ti}$ & 2.9519 & 4.6838 & 2.01 & 15 \\
\hline \multirow{2}{*}{37} & $\mathrm{Ti}$ & - & - & - & - \\
\hline & & & & & \\
\hline & TiC & 4.3163 & & 2.62 & 84 \\
\hline 55 & $\mathrm{TiC}$ & 4.3187 & & 3.12 & 18 \\
\hline 7 & TiC & 4.3184 & & 4.18 & 12 \\
\hline
\end{tabular}

\subsection{Microstructural Analysis of the Ti-C Milled Products}

\subsubsection{Microstructural Evolution before Ignition}

Fig. 3((a) and (b)) shows FESEM backscattered images for milled products of $\mathrm{Ti}_{50} \mathrm{C}_{50}$, sampled after milling for 25 and $36 \mathrm{~h}$. After $25 \mathrm{~h}$ milling, the metallic Ti particles are typically deformed, exhibiting a characteristic lamellar or pancake structure, while the graphitic flakes simply break into different sized particles. With increased milling time the Ti and graphitic particles are significantly refined to form heterogeneous mixtures of micro- and nano-particles of Ti and graphite (Fig. 3(b)). Fig. 3((c) and (d)) shows HRTEM images obtained for milled products sampled after 5 and $25 \mathrm{~h}$. After milling for $5 \mathrm{~h}$, the HRTEM images revealed regions that consist of curved or bent graphitic flakes and flower-like feature. Clearly, upon mechanical milling, the graphite sheets typically bend at different angles to form arch-like and flower-like morphological features. After $25 \mathrm{~h}$, the graphite particles were observed to form highly twisted or quasi-spherical graphitic morphologies. These twisted graphitic layers appear as loops that run into the titanium crystal, suggesting possible clumping of the graphitic flakes around the Ti crystal (insert in Fig. 3(d)).

Fig. 4(a) and (b) show a TEM image combined with SAD pattern (insert) and HRTEM (Fig. 4(b)) results obtained just prior to ignition ( $36 \mathrm{~h}$ of milling). In the TEM image (Fig. 4(a)), heterogeneous mixtures of $\mathrm{Ti}$ and $\mathrm{TiC}$ particles are observed, as confirmed in the SAD pattern (insert) where diffraction spots and rings match the d-spacing of (100), (002) and (101) of $\mathrm{Ti}$ and (111) of TiC peaks, as indexed. In the HRTEM image of the same sample (Fig. 4(b)), regions comprising amorphous C, spheriodised graphitic particles and crystal fringes that match $\mathrm{Ti}$ and $\mathrm{TiC}$ are observed. The detection of $\mathrm{TiC}$ crystals before ignition is consistent with the Raman spectroscopyresults (Fig. 7(a) and (b)). The TiC crystal was found to be located at the interface between the amorphous carbon $(a m C)$ and the nano-titanium crystal. 

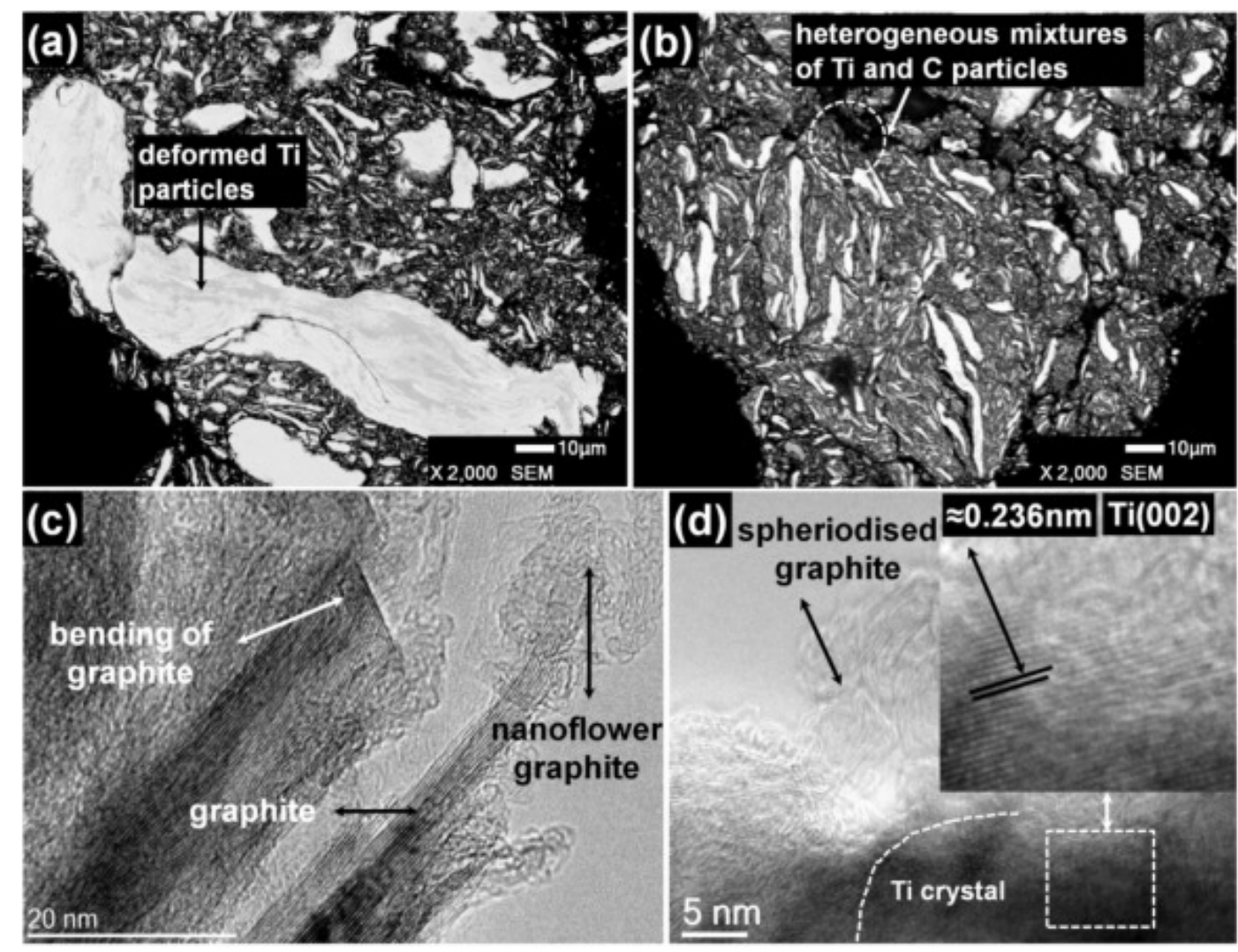

Fig.3. Milled products of $\mathrm{Ti}_{50} \mathrm{C}_{50}$ mixture sampled after milling (before ignition) for (a) $25 \mathrm{~h}$ showing FESEM image revealing heavily deformed Ti particles, (b) $36 \mathrm{~h}$ showing FESEM image revealing a heterogeneous mixture of $\mathrm{Ti}$ and graphite particles, (c) $5 \mathrm{~h}$, showing HRTEM image that displays regions of heavily deformed graphitic particles, (d) $25 \mathrm{~h}$, showing HRTEM revealing regions of nano-spheriodised graphitic particles and crystals of Ti.
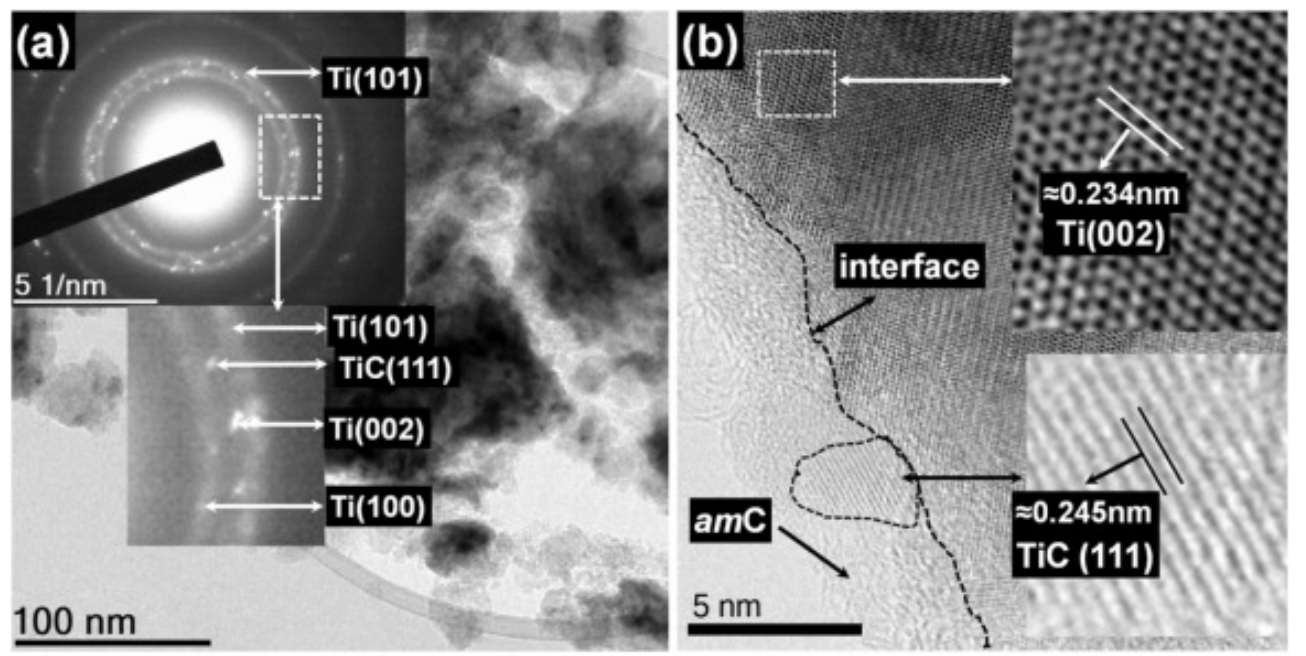

Fig.4. Milled products of $\mathrm{Ti}_{50} \mathrm{C}_{50}$ mixture sampled after milling (before ignition) for (a) $36 \mathrm{~h}$ showing TEM image and with SAD (insert) displaying spots/rings that match the d-spacing of $\mathrm{Ti}$ and $\mathrm{TiC}$ [2]; and (b) $36 \mathrm{~h}$ showing HRSTEM BF image which revealed fringes that match Ti and nano-TiC crystals (inserts) [2] 


\subsubsection{Microstructural Evolution after Ignition}

Fig. 5((a), (b) and (c)) shows FESEM results obtained for product sampled immediately after the ignition peak ( $37 \mathrm{~h}$ of milling). The reacted products comprise large platelets of $\mathrm{TiC}$ multilayers (Fig. 5(a)), TiC stacks (Fig. 5(b), and coarse TiC particles showing well-defined TiC grains bonded by melted titanium particles (white in colour). The local melting of the Ti particles may be attributed to the high heat released during the exothermic reaction at the point of ignition, heat sufficient to locally melt Ti and play a role in liquid phase sintering of the TiC during the period of the rapid grain growth. Fig. 5((d) and (e)) shows respective TEM bright-field (BF) combined with SAD (insert, and a corresponding dark-field image acquired using part of the $\mathrm{TiC}(220)$ ring reflection. The BF image clearly displays distinct upper and lower layers of $\mathrm{TiC}$ while its corresponding $\mathrm{DF}$ image reveals stacks of TiC multilayers. Additional HRTEM (Fig. 5(f)) reveals well-defined TiC multilayers.
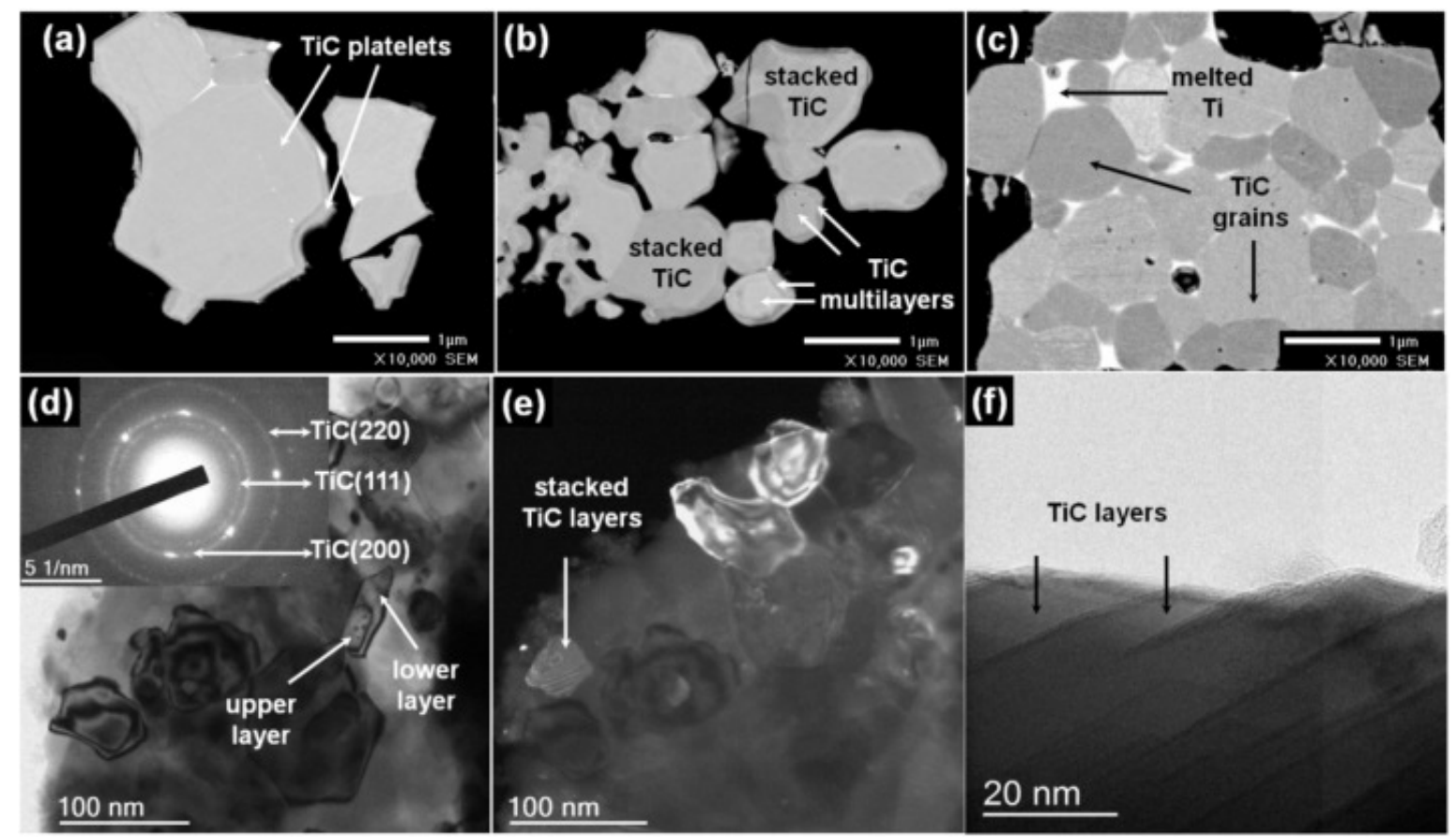

Fig.5. $\mathrm{Ti}_{50} \mathrm{C}_{50}$ reacted products sampled after milling for $37 \mathrm{~h}$ (after ignition) showing: backscattered FESEM images of (a) TiC platelets, (b) TiC stacks or layers, and (c) TiC grains bonded by melted Ti particles (d) TEM bright-field image displaying large TiC grains, and distinct upper and lower TiC layers, combined with SAD (insert) displaying rings that match TiC d-spacings, (e) associated TEM dark-field image acquired using TiC(220) ring reflection displaying regions of stacked TiC layers and coarse TiC particles, (f) HRTEM image displaying well-defined TiC multilayers.

\subsection{Raman Spectroscopy Analysis}

As reported in literature, stoichiometric TiC is non-Raman-active [36-38] due to the high inversion symmetry present in the $\mathrm{O}_{\mathrm{h}}$ point group (space group, Fm3m (225)) of the crystal structure of $\mathrm{TiC}$, and the screening effect of the valence electron present in most metallic bonds [36-38]. However, non-stoichiometric $\mathrm{TiC}_{1-\mathrm{x}}$ has been reported to be Raman-active, probably due to the presence of carbon vacancies, deformation defects and lattice imperfections contained in the off-stoichiometric $\mathrm{TiC}_{1-\mathrm{x}}$ structure. A Raman spectroscopic 
signal for off-stoichiometric $\mathrm{TiC}_{1-\mathrm{x}}$ has been reported by Lohse et al. [25], Klein et al. [36], Amer et al. [37], Huong et al. [39], Oláh et al. [40] and Pellegrino et al. [41]. Essentially, Klein et al. reported normal vibrations of off-stoichiometric $\mathrm{TiC}_{1-\mathrm{x}}$ bonds that corresponds to total vibrational $\Gamma=\mathrm{A}_{1 \mathrm{~g}}+\mathrm{E}_{\mathrm{g}}+\mathrm{T}_{2 \mathrm{~g}}$ of Raman-active modes [36]. Among these three Ramanactive modes for off-stoichiometric $\mathrm{TiC}_{1-\mathrm{x}}$, the $\mathrm{A}_{1 \mathrm{~g}}$ and $\mathrm{E}_{\mathrm{g}}$ has been reported to show very strong peak intensity while that of the $\mathrm{T}_{2 \mathrm{~g}}$ mode may display weaker band intensity.

\subsubsection{Raman Spectroscopy Analysis of the Starting Graphite, As- received TiC and the Ti-C Milled Products}

Fig. 6 shows Raman spectra obtained for different regions for particles of starting graphite and commercial TiC, acquired within frequency range of $100-2000 \mathrm{~cm}^{-1}$. Fig. 6(a) shows the Raman spectra obtained for graphite particles which display two characteristic bands which appear within frequency range of $1331-1350$ and $1580-1588 \mathrm{~cm}^{-1}$. These bands are typically assigned to respectively to $\mathrm{A}_{1 \mathrm{~g}}$ and $E_{2 \mathrm{~g}}$ Raman-active modes $[\underline{25}, \underline{36}, \underline{42}]$. The $E_{2 \mathrm{~g}}$ active modes are vibrations due to in-plane bond stretching motion for pairs of carbon $\mathrm{sp}^{2}$ bond atom while the $\mathrm{A}_{1 \mathrm{~g}}$ mode becomes active due to breakdown of the translational and local lattice symmetry, often summed up as the presence of disorderliness in the atomic arrangement of graphite [42]. Typically, the bands are often referred to as the defective (D-band) and graphitic (G-band) bands respectively [36, $\underline{42}]$. As shown in Fig. 6((a), the intensity of the Gpeak appears very high and strong as compared to the defective peak. This implies that the starting graphite contained some particles that are defective in structure.
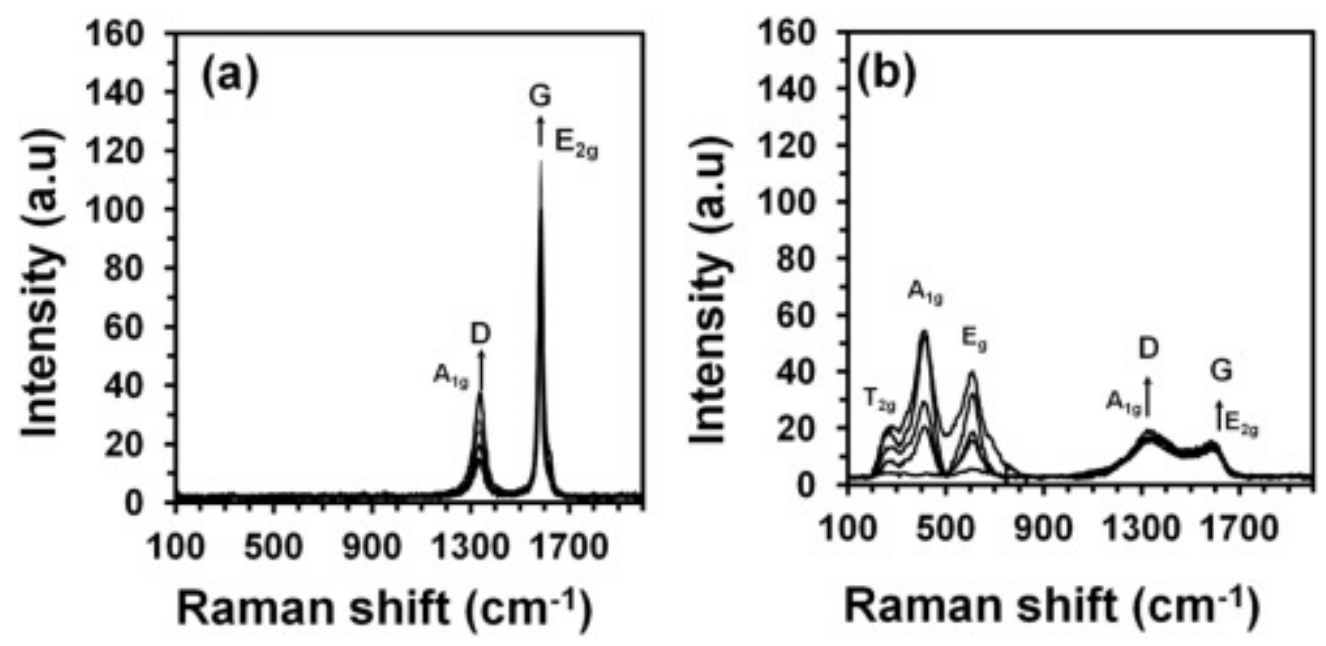

Fig.6. Raman spectra obtained from (a) starting graphite; and (b) commercial TiC (Aldrich®) powders.

In order to determine the Raman activeness of the Ti-C milled products, commercial TiC, supplied by Aldrich ${ }^{\circledR}$, with a purity of $98.9 \%$ was examined, as shown in Fig. 6(b). Raman spectra obtained for the commercial TiC powder are observed to display five characteristic peaks. Two of the peaks are broad and are located at 1331 and $1589 \mathrm{~cm}^{-1}$, assigned respectively to $A_{1 \mathrm{~g}}$ and $E_{2 \mathrm{~g}}$ Raman-active modes of carbon while the other three peaks that are located at 268, 426 and $608 \mathrm{~cm}^{-1}$ are reportedly associated to signal of Ti-C bond vibrations of off-stoichiometric $\mathrm{TiC}_{1-\mathrm{x}}[\underline{25}, \underline{37]}$. According to Klein et al. [ㅌ] $]$, these three peaks are assigned to $\mathrm{T}_{2 \mathrm{~g}}+\mathrm{A}_{1 \mathrm{~g}}+\mathrm{E}_{\mathrm{g}}$ Raman-active modes. The $\mathrm{A}_{1 \mathrm{~g}}$ and $\mathrm{E}_{\mathrm{g}}$ peaks, typically located in the optical phonons region are vibrational bond motion due to the carbon atom while the $T_{2 g}$ peak located within the acoustic region is associated with the titanium motion 
[36]. This implies that the vibrational bond contribution due to carbon atoms present in the off-stoichiometric $\mathrm{TiC}_{1-\mathrm{x}}$ is probably stronger than motion that comes from the titanium bonded atoms. It was also observed that the intensity of Raman peaks obtained for the starting graphite and the commercial TiC appears to differ for different regions of the particles that are probed with the beam. Such difference is typically attributed to variation in surface roughness of the powder particles. During acquisition, spectra obtained for surfaces that are not relatively flat may likely diffract light not perpendicular to the incident light thereby allowing the scattered light back to the detector. This may partly explain the relative difference in the intensity height of the peaks obtained for the starting graphite and commercial TiC, a result that is consistent with the previous observation of Lohse et al. [25].
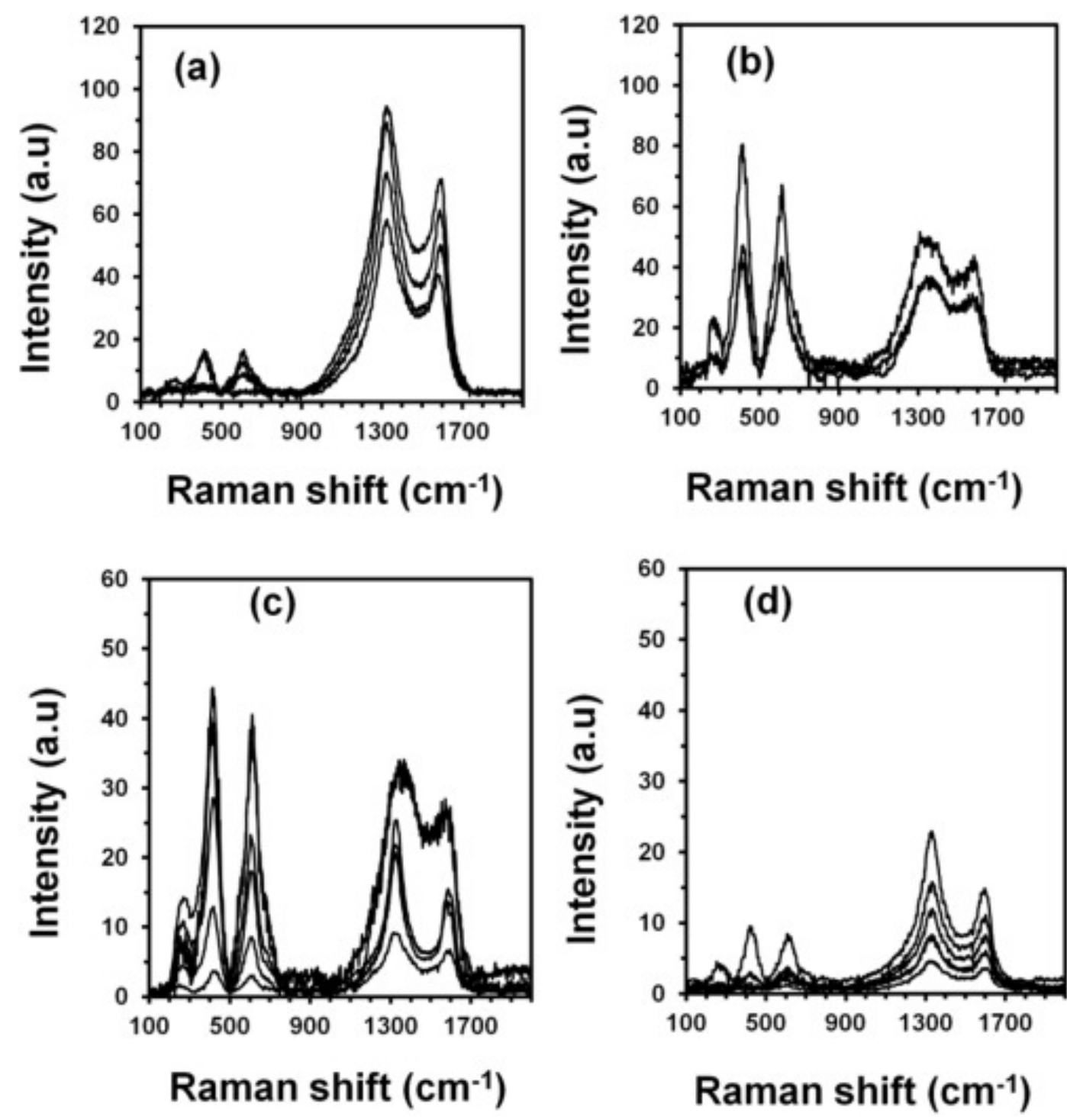

Fig.7. Raman spectra obtained for milled products of $\mathrm{Ti}_{50} \mathrm{C}_{50}$, sampled after milling (before ignition) for (a) $25 \mathrm{~h}$, (b) $36 \mathrm{~h}$, (c) $37 \mathrm{~h}$ (immediately after ignition), and (d) $47 \mathrm{~h}$ (further milling after ignition).

Fig. 7 shows the Raman spectra obtained for regions of $\mathrm{Ti}_{50} \mathrm{C}_{50}$ particle mixture, sampled after milling for 25 and $36 \mathrm{~h}$ before ignition, $37 \mathrm{~h}$ (immediately after ignition) and $47 \mathrm{~h}$ (further milling after ignition). Raman spectra acquired for different particle regions, sampled after milling for 25 and $36 \mathrm{~h}$ show the five characteristic peaks that are consistent with off- 
stoichiometric $\mathrm{TiC}_{1-\mathrm{x}}$ and graphitic bands, also observed by Amer et al. [37], Klein et al. [36] and Lohse et al. [25]. As shown in Fig. 7(a), the intensity of the off-stoichiometric $\mathrm{TiC}_{1-\mathrm{x}}$ peaks obtained after milling for $25 \mathrm{~h}$ appear very weak when compared to those that are sampled after milling for $36 \mathrm{~h}$ (Fig. 7(b)). Closer inspection reveals that the intensity of the off-stoichiometric $\mathrm{TiC}_{1-\mathrm{x}}$ relative to the intensity of the graphite peaks increases significantly after milling for $36 \mathrm{~h}$ (Fig. 7(b)). Such increase in the intensity of the $\mathrm{TiC}_{1-\mathrm{x}}$ is probably due to increase in the volume fraction of the $\mathrm{TiC}_{1-\mathrm{x}}$ that is present in the milled product, consistent with the investigation of Lohse et al. [25]. Also, the relative intensity of the defective over the graphitic peaks of graphite reduces greatly, possibly suggesting the formation of nanostructured particle sizes of graphite. Moreover, the $\mathrm{TiC}_{1-\mathrm{x}}$ peaks are slightly shifted to higher frequency values compared with those that are sampled after $25 \mathrm{~h}$ of milling. Such higher frequency shift is reportedly attributed to increase in the carbon vacancies as well as increase in density of accumulated lattice defects [43].

Immediately after ignition (Fig. 7(c)), the Raman spectra display signals that match offstoichiometric $\mathrm{TiC}_{1-\mathrm{x}}$ and graphite particles. The $\mathrm{TiC}_{1-\mathrm{x}}$ peak intensities of the just reacted product is slightly decreased, compared to the sample just before ignition, however; there are some local regions that show increases in the Raman intensities. This result may indicate that the just reacted products are formed with high deficit of carbon atoms [44] and still contain high proportions of off stoichiometric $\mathrm{TiC}_{1-\mathrm{x}}$. However, the intensities of the offstoichiometric $\mathrm{TiC}_{1-\mathrm{x}}$ and graphite peaks greatly reduces as milling time is increased to $47 \mathrm{~h}$. This reduction in the intensities may be partly due to further reaction between the offstoichiometric $\mathrm{TiC}_{1-\mathrm{x}}$ and the graphite to produce stoichiometric $\mathrm{TiC}$, the latter a phase being known not to produce a Raman signal [25].

\subsection{X-Ray Photoelectron Spectroscopy Analysis of Ti-C Milled Products}

Fig. 8 shows deconvoluted core-levels high resolution XPS spectra obtained for products of $\mathrm{Ti}_{50} \mathrm{C}_{50}$ that are sampled just prior to ignition ( $\left.36 \mathrm{~h}\right)$ and just after ignition ( $\left.37 \mathrm{~h}\right)$.
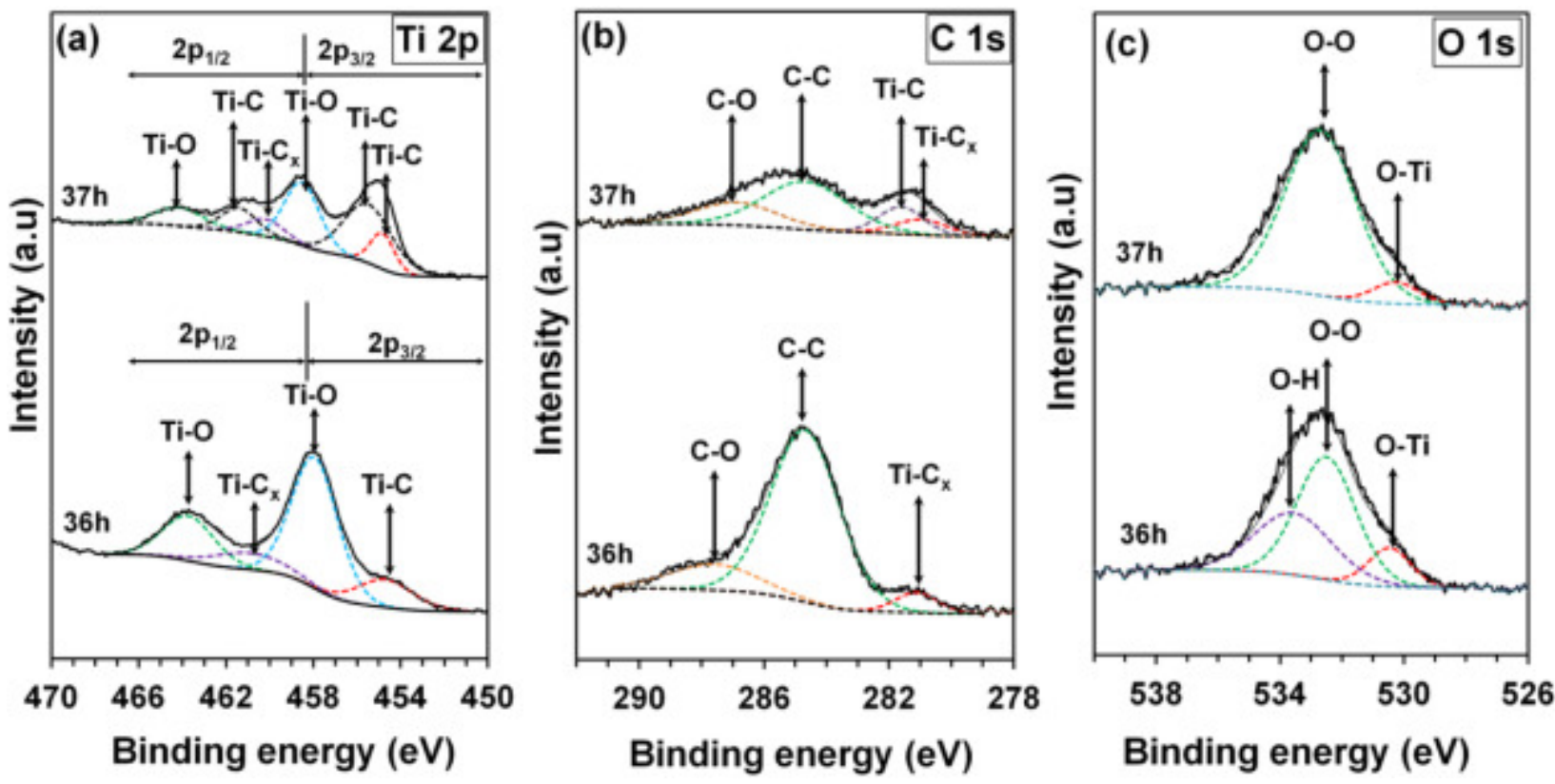
Fig.8. High resolution XPS spectra deconvolution obtained for $\mathrm{Ti}_{50} \mathrm{C}_{50}$ products that are sampled just before ignition (after $36 \mathrm{~h}$ of milling) and just after ignition (after $37 \mathrm{~h}$ of milling) ignition showing: (a) Ti (2p), (b) C (1s), and (c) O (1s) core-levels.

\subsubsection{Deconvolution of the Ti $(2 p)$}

Fig. 8(a) show deconvoluted Ti (2p) core-levels high resolution XPS spectra obtained for products that was sampled just before ignition ( $36 \mathrm{~h})$ and just after ignition $(37 \mathrm{~h})$. Just before ignition, the XPS spectrum obtained for the milled product (Fig. 8(a)(36 h)) shows three distinct peaks that was precisely fitted to form two splitting doublets. The doublet with two peaks position located at $\mathrm{Ti}\left(2 \mathrm{p}_{1 / 2}\right) 464.4 \mathrm{eV}$ and $\mathrm{Ti}\left(2 \mathrm{p}_{3 / 2}\right) 458.6 \mathrm{eV}$ is typically attributed to oxide states of Ti metal $[\underline{45}, \underline{46}]$. This result shows that oxygen is bonded to titanium at the surface, a result that is consistent with several workers $[\underline{1}, \underline{7}, \underline{47}]$. The other doublet splitting with peaks position located at $\mathrm{Ti}\left(2 \mathrm{p}_{1 / 2}\right) 460.9 \mathrm{eV}$ and $\mathrm{Ti}\left(2 \mathrm{p}_{3 / 2}\right) 454.8 \mathrm{eV}$ binding energies (BEs) is typically assigned to Ti_C bonds [47-49]. The observation of Ti_C chemical bonds in the pre-ignition sample is consistent with the Raman result obtained for the same sample (Fig. 8(b)). This observation is also consistent with the investigation of Dorofeev et al. [1] and Wu et al. [7]. However, Dorofeev et al. [1] attributed the observation of the initial $\mathrm{Ti}$ _C bonds to proportions of amorphous $\mathrm{TiC}$ present in the milled product. This explanation was given because the crystalline TiC had not formed yet according to the XRD data. Wu et al. [7] attributed such early Ti_C formation to a transitional bonded state that occurs between $\mathrm{Ti}$ and graphite during mechanical milling before the self-propagating reaction. However, in the current case, the results obtained from TEM combined with SAD (Fig. 4(a)) and HRTEM (Fig. 4(b)) represent evidence that the newly formed TiC, is crystalline, rather than amorphous as earlier suggested by Dorofeev et al. [1].

Immediately after ignition, XPS results (Fig. 8(a)(37 h)) reveal three distinct peaks and a shoulder peak that was precisely fitted to form two splitting doublets. The peaks located at $\mathrm{Ti}$ $\left(2 \mathrm{p}_{1 / 2}\right) 464.8 \mathrm{eV}$ and $\mathrm{Ti}\left(2 \mathrm{p}_{3 / 2}\right) 458.5 \mathrm{eV}$ bear bond features that match oxygen bonded to titanium. While, the peak positions located at $\mathrm{Ti}\left(2 \mathrm{p}_{1 / 2}\right) 461.1 \mathrm{eV}$ and $\mathrm{Ti}\left(2 \mathrm{p}_{3 / 2}\right) 455.2 \mathrm{eV}$ are attributes of $\mathrm{Ti} \_\mathrm{C}$ bond features. Interestingly, the peak intensity of the $\mathrm{Ti} \_\mathrm{C}$ bond relative to that of the sample taken out before ignition (Fig. 8(a)(36)) increases greatly while at the same time shifted slightly to higher energies values. The higher chemical shift is also observed to occur for the Ti__o bonds, suggesting that the entire spectrum is slightly shifted to higher binding energies. Such shifts are an indication that the initial $\mathrm{Ti} \_\mathrm{C}$ bonds have relatively stronger interaction and bonding, not merely a transitional bonded state, as earlier suggested by Wu et al. [32]. The higher peak intensity of the Ti__ $\mathrm{C}$ bonds that was detected immediately after ignition is a direct consequent of formation of more volume content of TiC, as quantitatively estimated using the elemental analysis present in the XPS software (results not presented here).

\subsubsection{Deconvolution of the C (1s)}

Fig. 8(b) shows the C (1s) core-level high resolution XPS spectra obtained for milled product that was sampled just before $(36 \mathrm{~h})$ and just after $(37 \mathrm{~h})$ ignition. Just before ignition, the XPS spectrum obtained for the milled product (Fig. 8(b)(36)) display one intense peak and two shoulder peaks. These three peaks were fitted three Gaussian-Lorentzian curves with binding energies located at $281.0 \mathrm{eV}, 284.7 \mathrm{eV}$ and $286.9 \mathrm{eV}$. The $281.0 \mathrm{eV}$ peak is typically consistent with Ti_C bond. Since the bond is found to occur before the ignition point, assigning a characteristic Ti- $\mathrm{C}_{\mathrm{x}}$ bond is probably appropriate to differentiate it from the conventional known $\mathrm{Ti} \_\mathrm{C}$ bond. Comparing the conventional XPS binding energies of $\mathrm{Ti}$ _ $\mathrm{C}$ bonds reported in literature $(281.1-282.0 \mathrm{eV})[\underline{7}, \underline{47}, \underline{49}, \underline{50}]$ with the $281.0 \mathrm{eV}$ obtained in 
this investigation, which slightly lower in binding energy, may possibly suggest that the characteristic Ti- $\mathrm{C}_{\mathrm{x}}$ bond is likely formed with strong Ti-C bond interaction, not merely a transitional bonded state as suggested by $\mathrm{Wu}$ et al. [7]. So the characteristic Ti- $\mathrm{C}_{\mathrm{x}}$ peak is likely associated with the presence of off-stoichiometric $\mathrm{TiC}_{\mathrm{x}}$. The fitting of the $\mathrm{C} 1 \mathrm{~s}$ core levels which are associated with an intense $284.7 \mathrm{eV}$ peak and a shoulder $286.9 \mathrm{eV}$ peak can be attributed to $\mathrm{C} \_\mathrm{C}$ and $\mathrm{C} \_\mathrm{O}$ bonds respectively.

Just after ignition, the $\mathrm{C}(1 \mathrm{~s})$ core-level spectrum display two distinct broad peaks that are fitted with four Gaussian-Lorentzian curves. The binding energies of these peaks are located at 281.0, 281.6, 284.4 and $286.7 \mathrm{eV}$. The BEs of 281.0 and $281.6 \mathrm{eV}$ can be assigned to features of $\mathrm{Ti} \_\mathrm{C}$ bonds $[\underline{7}, \underline{47}, \underline{49}, \underline{50}]$. The peak positioned at $281.6 \mathrm{eV}$ is probably due to formation of stoichiometric quantities of the Ti_C because its component concentration was estimated (using XPS elemental analysis) to be larger than the component of the peak located at $281.0 \mathrm{eV}$. This result clearly demonstrate that even after ignition quantities of offstoichiometric $\mathrm{TiC}$ are also present in the just reacted products, an observation consistent with the Raman result obtained for the same product (Fig. 7(c)). The peak located at 284.4 is typically assigned to features of $\mathrm{C} \_\mathrm{C}$ bonds of amorphous graphite state. Compared to this peak, the equivalent peak in the milled product obtained just prior to ignition is of significantly decreased intensity (Fig. 8(b)). Such a decrease in atomic concentration of the C - C component is probably due to the exothermic reaction which occurs at ignition resulting to depletion of the concentration of the graphite.

\subsubsection{Deconvolution of the $O$ (1s)}

Deconvolution of the $\mathrm{O}$ 1s core-levels indicates that the surfaces of the milled products sampled just before $(36 \mathrm{~h})$ and just after $(37 \mathrm{~h})$ ignition are contaminated with oxygen and absorbed water, a result that is consistent with earlier report that indicate the formation of oxide film that is present on the surface of titanium powder [51]. Fig. 8((c) (36 h)) shows the deconvolution of the O (1s) XPS spectrum from the milled product before ignition. Oxygen bonded with titanium; and oxygen bonded with hydrogen, attributed to presence of absorbed water, are observed. XRD, HRTEM and TEM/SAED analysis performed on the same sample with the same exposure to air do not indicate the formation of these oxide contaminants. XPS is very surface sensitive and is capable of detecting features that are located at the surface, even in minute concentrations beyond the detection limits of the other techniques. However, another possibility is that the surface oxidation of titanium picked up by XPS was a consequence of the longer product handling times of the particular samples before XPS analysis.

The $\mathrm{O}$ 1s core levels of the spectrum acquired immediately after the ignition point also reveal surface oxide contamination (Fig. 8(c) (37 h)). Based on the detection of surface oxide film by XPS, there is high possibility that the off-stoichiometric TiC detected by the Raman spectroscopy is not completely free from surface contamination, so the non-stoichiometric Ti$\mathrm{C}_{\mathrm{x}}$ bonds may be more accurately is referred to as oxy non-stoichiometric $\mathrm{TiC}_{\mathrm{x}} \mathrm{O}_{\mathrm{y}}$, consistent with observations of [1ㅣ].

\subsection{Electron Energy Loss Spectroscopy Analysis of the Ti-C Milled Products}

High spatial resolution STEM combined with EELS was performed in order to investigate chemical bonding environment of milled powders that were sampled just prior to and just after ignition. Further chemical quantification and EELS study performed on products that were milled for $75 \mathrm{~h}$ in order to study the stoichiometry transition of the TiC products with increase milling time after ignition. 


\subsubsection{Electron Energy Loss Near-edge Structure on the $C K$ - and $T i L_{2,3^{-}}$ Edges}

Fig. 9(a) shows a high magnification STEM-high angle annular dark field (HAADF) image (marked with boxes indicating the selected region of interest for EELS spectrum acquisition), from an area corresponding to the region of the STEM bright field image (Fig. 4b)). Fig. 9(b) and (c) shows plots of the corresponding $\mathrm{C} \mathrm{K}$ - and $\mathrm{Ti} \mathrm{L}_{2,3}$-edge shapes obtained for the selected regions after background subtraction, for milled product sampled just prior to ignition (36 h). The STEM-HAADF image (Fig. 9(a)) of the same region of Fig. 4(b), reveals diverse thickness/mass variations that may represent different chemical compositions. The EELS obtained from the areas marked with boxes include corresponding C K-edge electron energy loss near-edge structure (ELNES) spectra and reveal features that can be attributed to both: an amorphous or highly deformed graphitic structure (spectra labelled "I" and "II") [52], and TiC (spectra labelled "III") [53-56]. In the C K-edge plots (Fig. 9(b)), the ELNES shape of TiC (spectrum labelled "III") was observed to display five distinct broad peaks, labelled using the same notation as earlier reported by Pflüger et al. [56], Craven et al. [55]

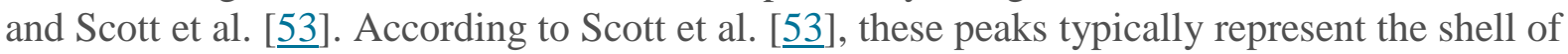
atoms that are present in the TiC bonding states. Scott et al. [53] reported the composition of the atoms present in each of these shells as: $6 \mathrm{Ti}$ in shell 1; $12 \mathrm{C}$ in shell 2; $8 \mathrm{Ti}$ in shell 3; $6 \mathrm{C}$ in shell 4; $24 \mathrm{Ti}$ in shell 5; $24 \mathrm{C}$ in shell 6; and $12 \mathrm{C}$ in shell 7 equating to 93 atoms in the TiC. Using the analysis of Scott et al. [프], it implied that the peak labelled "1" in the C Kedge plot will represent scattering from the first shell containing the six titanium atoms while the second shell (Peak 2) is due to excitation from the twelve (12) carbon atoms.
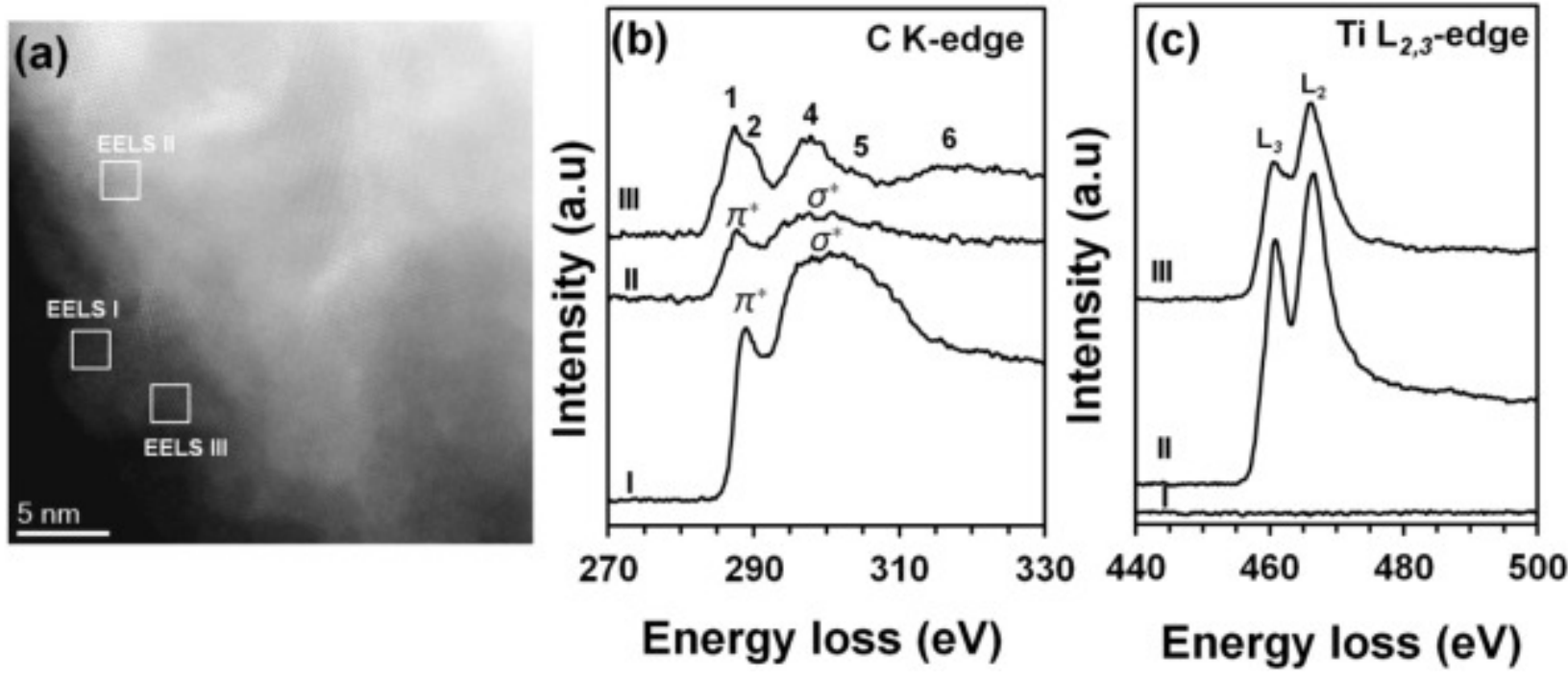

Fig.9. Milled products of $\mathrm{Ti}_{50} \mathrm{C}_{50}$, sampled just before ignition (36 h) showing: (a) an STEMHAADF image marked with boxes indicating selected region of interest for EEL spectra acquisition, and (b) and (c)) the comparison of C K-edge and Ti $\mathrm{L}_{2,3}$-edge ELNES shapes obtained at the selected regions of interest I-III.

As shown in Fig. 9(b), the C K-edge feature that matches the deformed graphitic structure contained two peaks with onset core-level energy loss value of $285 \mathrm{eV}$. The two peaks typically represent the $\pi^{*}$ and $\sigma^{*}$ states transition of graphite $[52,57]$. The first lower peak, which appears at an energy loss of $289 \mathrm{eV}$, stems from scattering to the $\pi^{*}$ states while the second peaks, located at $301 \mathrm{eV}$, represent a transition from the $1 \mathrm{~s}$ to the $\sigma^{*}$ band [57]. The $\mathrm{C}$ 
K-edge ELNES feature of Spectrum (II) is similar to ELNES shape of Spectrum "I", however, the $\pi^{*}$ and $\sigma^{*}$ peaks appear to have lower intensities as compared to the intensity of the peaks in Spectrum "I". In the bright-field STEM image (Fig. 4(b)), the region of spectrum "I" corresponds to a well-defined titanium crystal. However, in the EELS spectrum "II", a graphitic feature was observed to be associated with the Ti microstructure, suggesting the probability of the graphite particles surrounding or clumping around the Ti particles. In the respective Ti $\mathrm{L}_{2,3}$-edges (Fig. 9(c)), there was no $\mathrm{Ti} \mathrm{L}_{2,3}$-edge structure present in spectrum "I", indicating the absence of Ti particles in that environment while the edge-structures for spectra "II" and "III" are very distinct with clear differences in their peak intensity and further splitting within the shell band. The difference in the peak intensity can be attributed to slight differences in the first coordination shell bonds for the Ti atoms [58]. While the distinct spitting of the lower energy $\mathrm{Ti}^{\mathrm{L}} \mathrm{L}_{3}$ and higher energy $\mathrm{Ti} \mathrm{L}_{2}$ edges for "III" as compared to spectra "II" is likely be due to the differences in the valence state and coordination of the $\mathrm{Ti}$ atoms within the Ti-C bond in $\mathrm{TiC}$ and $\mathrm{Ti} \_\mathrm{Ti}$ bond in metallic $\mathrm{Ti}$ [58].
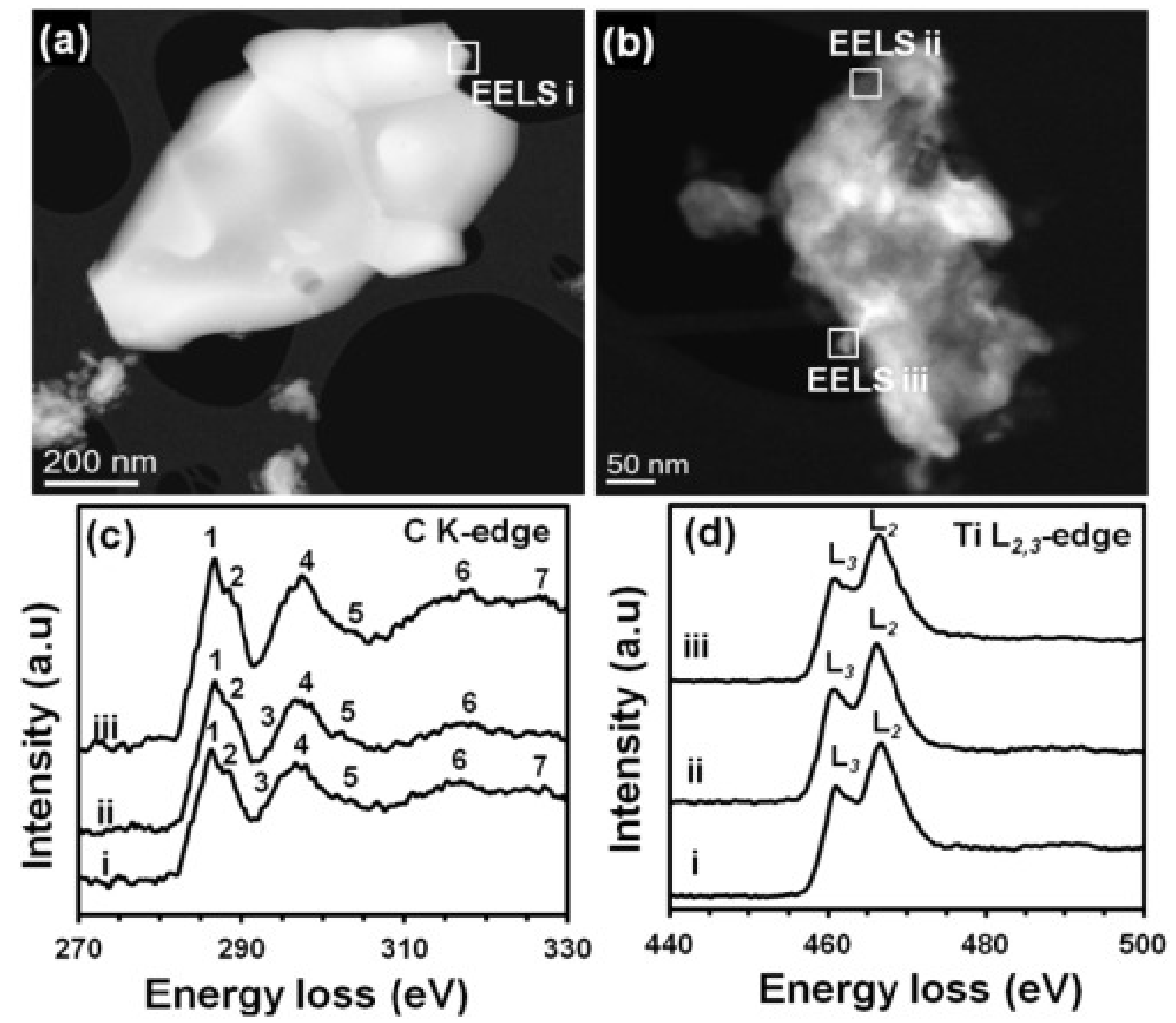

Fig.10. Reacted products of $\mathrm{Ti}_{50} \mathrm{C}_{50}$ showing (a) STEM-HAADF image from product sampled just after ignition ( $37 \mathrm{~h})$, (b) STEM-HAADF from product sampled after milling for $75 \mathrm{~h}$, both (a) and (b) marked with small boxes indicating selected region of interest for EEL spectra acquisition; while (c) and (d) shows the comparison of C K-edge and Ti $\mathrm{L}_{2,3}$-edge ELNES shapes obtained at the selected regions of interest for samples milled for $37 \mathrm{~h}$ (i) and $75 \mathrm{~h}$ (ii-iii). 
Just after ignition (after $37 \mathrm{~h}$ of milling), the STEM image (Fig. 10(a)) typically display welldefined TiC grains while the corresponding plots of the $\mathrm{C} \mathrm{K}$ - and $\mathrm{Ti} \mathrm{L}_{2,3}$-edges obtained at the selected regions revealed ELNES shapes that are consistent with TiC phase $[\underline{53}, \underline{54}, \underline{56}]$. However, the $\mathrm{C}$ K-edge peaks obtained for the just reacted TiC product was observed to shift to a lower energy loss value when compared to that of TiC formed just prior to ignition (Fig. 9(b)). After milling for $75 \mathrm{~h}$, the plots of the $\mathrm{C} \mathrm{K}$ - and $\mathrm{Ti} \mathrm{L}_{2,3}$-edges are also consistent with ELNES shape of TiC (Fig. 10(c) and (d)). In the respective Ti L2,3-edges (Fig. 10(d)), further spitting of the lower energy loss of $\mathrm{Ti}_{3}$ and peaks broadening was found to occur, a result attributed to resonance scattering within the shells of the neighbouring atoms [묘].

\section{Discussion}

Raman spectroscopy confirmed the formation of off-stoichiometric $\mathrm{TiC}_{1-\mathrm{x}}$ before the ignition point $[\underline{25}, \underline{59}]$, while XPS revealed binding energies that match TiC (Fig. 8(a) and (b)), and additional oxygen bonded features (Fig. 8(c)). The appearance of the oxygen bonded features is attributable to the presence of oxide skins coating the surfaces of the milled powders. Electron microscopy combined with electron diffraction (Fig. 4(a) and (b)) revealed the $\mathrm{TiC}$ crystals formed before ignition. Pre-ignition formation of $\mathrm{TiC}\left(\right.$ or $\mathrm{TiC}_{1-\mathrm{x}}$ ) is believed to be due to a reaction at the interface between the heavily deformed $\mathrm{Ti}$ particles and graphitic debris [2], possibly promoted by high induced localized temperature [60-62], high induced pressure $[\underline{21}, \underline{63}]$, accumulation of lattice defects which could lower the activation energies for reaction between the constituents $[7, \underline{15}]$, and the mobility of both Ti and $\mathrm{C}$ atoms due to local regions of high defect density accumulations $[\underline{4}, \underline{64}, \underline{65}]$.

To gain more understanding on the likely sequence of growth of the TiC grains, samples taken immediately after ignition were examined using FESEM. The FESEM images (Fig. 5) revealed different morphological features of the TiC, including thin-plated $\mathrm{TiC}$ multilayers, TiC stacks, and coarse but well-defined TiC grains (consisting imperfect units of hexagonal and octahedron TiC grains). Stoichiometric TiC is generally faceted with a face-centred cubic NaCl-type structure and octahedron growth unit, as illustrated in Fig. 11(a). When Fig. 11(a) viewed along the direction perpendicular to the TiC (111) plane, a simple hexagonal shape of atomic arrangement of titanium (large spheres) and graphite (small spheres) can be seen (Fig. 11(b)) [44]. This likely explains why some hexagonal features of $\mathrm{TiC}$ are observed in the FESEM images (Fig. 5(c)). Under normal solidification conditions, the growth of the TiC will involve the bonding of the titanium and the carbon atoms to form an atomically stable octahedron unit of $\mathrm{Ti}^{-\mathrm{C}_{6}}$., implying that, each of the titanium atoms (centred) will be surrounded by six carbon atoms (corners or edges) or vice-versa, as illustrated in Fig. 11(c). However, the microstructural evolution of TiC via MSR is typically off-stoichiometric $\mathrm{TiC}_{\mathrm{x}}$ [3-5], implying that the $\mathrm{TiC}_{\mathrm{x}}$ is formed with high proportions of carbon vacancies (previously reported to be located especially at the corners or edges), as schematically illustrated in Fig. 11(d) [44].

The presence of thin-plated and stacks of multilayers of TiC present in the just reacted products may likely indicate a unique step that occurred during the period of the rapid nucleation and growth sequence of $\mathrm{TiC}$ at ignition. The mechanism involved in the formation of these thin-plated $\mathrm{TiC}$ multilayers likely commences with the formation of several TiC nuclei at the start of the MSR (Fig. 1). Presumably, from the start of the temperature increase to where it reaches its maximum value, these TiC nuclei grow and spontaneously coalesce to form the first layer of TiC. A newly grown TiC layer in the system might deposit on top of the first $\mathrm{TiC}$ layer and instantaneously generate new steps. Upon continuous generation of these steps, newly arrived TiC layers will repeatedly be deposited 
on the previous layers forming stacks of TiC layers (Fig. 5(a), (b), (d) and (e)). These TiC layers can then continue to grow through a layer-by-layer process until a fully grown $\mathrm{TiC}$ grain is formed. Whether a perfect or an imperfect TiC grain is formed is likely dependent on the temperature, time and other thermodynamic conditions that could influence its growth sequence $[\underline{44}, \underline{66}]$.

\section{(a)}

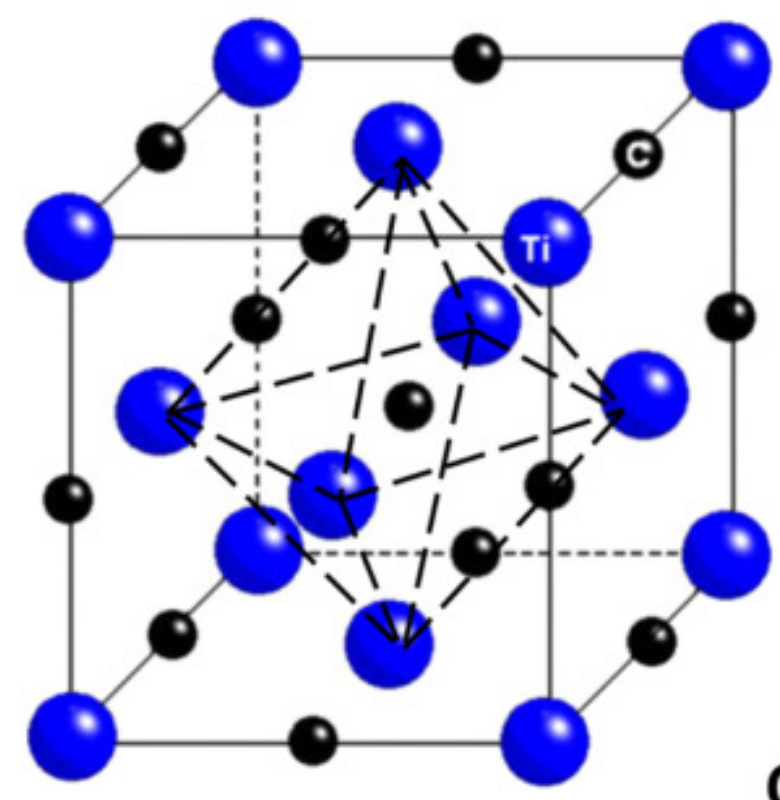

(b)
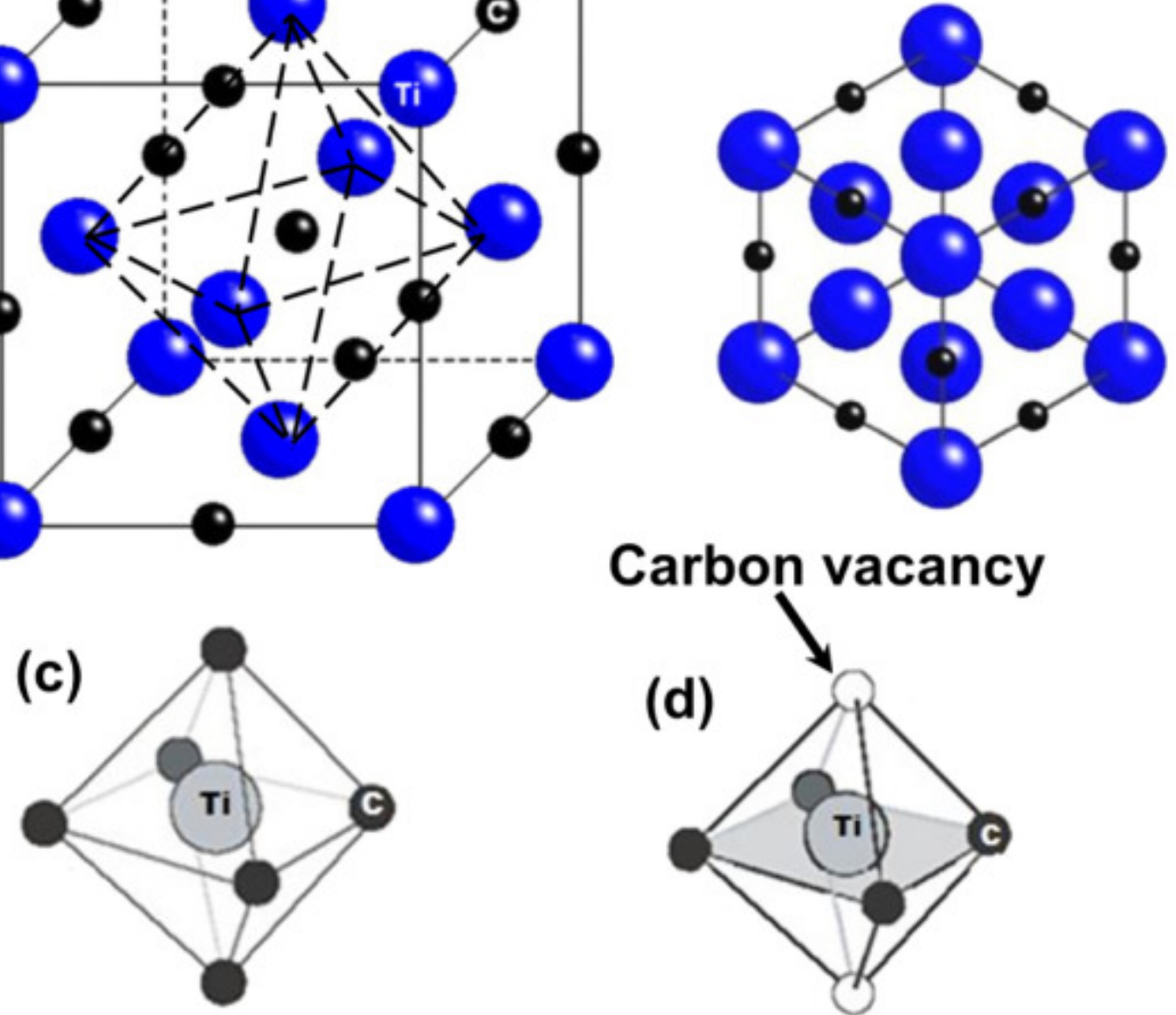

Carbon vacancy

(d)
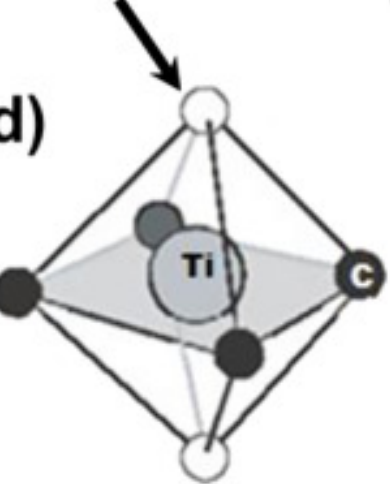

Fig. 11. (a) fcc-TiC crystal structure [44], (b) projection of Ti-C atoms along the [111] direction [44], (c) Ti-C 6 stoichiometric octahedron unit and (d) Ti- $\mathrm{C}_{\mathrm{x}}$ non-stoichiometric octahedron unit showing carbon vacancies

For the case of two or multiply stacked TiC crystals sharing a common edge or corner (as shown in Fig. 5(b)), an edged-shared of TiC growth is likely displayed, such as that earlier reported by Song et al. [44] during self-propagating high temperature synthesis (SHS) of TiC from thermally heated compacts of Ti and carbon black. As shown in the FESEM image (Fig. 7(b)), a series of stacked TiC layers were observed linking with neighbouring layers, mostly at the edges or corners. Typically, the linking of one stack with another at the edges or corners may likely occur if there are carbon deficiencies present around those corners. And if carbon deficient exits in form of vacancies in the corner of the TiC layers, it will be highly unlikely or difficult for a new layer to be deposited on top of the facets. Rather, it is will be thermodynamically favourable for the stacks of $\mathrm{TiC}$ to link with another stalk at the edges or 
corners in order for $\mathrm{TiC}$ to evolve into a perfect hexagonal or octahedron units of TiC. The presence of these stacked TiC layers linking with another stack of layers therefore is evidence that the edged-shared mechanism of grain growth is also present in MSR.

More interestingly these stacks of TiC layers are different sizes. As shown in the FESEM (Fig. 5(b)) and TEM (Fig. 5(d)) images, the size of the lower layers was found to be larger than the upper layers. This result appears inconsistent with the explanation of the Wulff formula with respect of the shape and dimension of a crystals during nucleation and growth [67]. According to Wulff, the ratio of the surface energies $\left(\gamma_{i}\right)$ and the distances $\left(h_{i}\right)$ from a point to the centre within a crystal facet is a constant under equilibrium condition, that is, $\gamma_{i} / h_{i}=$ constant [67]. The direct interpretation of the Wulff formula suggests that the dimensions of the crystal facet from the center to edges for all layers should be the same. However, this is not the case for evolution of TiC by MSR. Presumably, the heat that is available for nucleation and growth for subsequent layers after the formation of the first TiC layer may varies significantly with position or time inside the mill. This rapid reduction in the temperature with time is probably caused by heat losses to the environment. The heat losses may probably reduce the rate at which the generation of new steps and the speed of growth for subsequent $\mathrm{TiC}$ layers occur. This was clearly seen for the reacted TiC layers where the lower layer is larger than the upper layer, a result that is consistent with the observation of Zhang et al. during SHS synthesis of TiC [ㅎ6].

Spatially-resolved high resolution STEM combined with EELS has revealed the heterogeneous nature of the milled products and the transition of the pre-existing offstoichiometric $\mathrm{TiC}_{1-x}$ towards stoichiometry after ignition with increase milling time. This was typically revealed from the C K-edge plots obtained for products that are sampled prior to and after ignition. On closer inspection of the C K-edge plots obtained for the products, the shapes of the ELNES of TiC revealed slight differences in the intensity of peaks and corelevel splitting, especially for the peaks labelled "4" and "6" (Fig. 10(c)(i) and (iii)). As reported, the core-level shifting is connected to the amount of charge transfer between Ti and $\mathrm{C}$ and the bonding characteristics [46]. As shown in the C K-edge plots obtained for the just reacted TiC (Fig. 10(i)), peak " 4 " and "6" appear to have higher intensity as compared with the same " 4 " and " 6 " peaks for products that are obtained prior to ignition (Fig. 9(b)(III)). Another obvious significance is the low energy separation between peak " 1 " and "2" and the appearance of peak " 6 " and " 7 " in the edge structures obtained for the just reacted TiC (Fig. 10(c)(i)), when compared to larger peak separation and absence of peak "6" and "7" for the TiC C K-edge structure obtained prior to ignition (Fig. 9(b)(III)). As suggested by [ [53], such a small energy separation for the $\mathrm{TiC}$ is probably due to extended overlapping between the Ti-3d and C-2p states during chemical bonding, which is a clear indication of stronger interaction of $\mathrm{Ti}$ and $\mathrm{C}$ bonds.

In the case of the reduced peak intensity (measured after background subtraction) for peaks labelled " 4 " and " 6 " in the C K-edge ELNES obtained for products that are sampled prior to ignition (Fig. 9(III)), this result is attributable to the presence of carbon deficient sites (vacancies) in the TiC structure. As reported by Scott et al. [53], the second shell (Peak 2) is due to excitation from the twelve (12) carbon atoms while peak " 4 " and "6" are typically due to intrashell and intershell scattering within the first carbon shell (second shell). This suggests that as the carbon becomes increasing deficient in the TiC structure, scattering from the second shell (carbon shell) may likely reduce. Clearly, Peak "4" will be strongly affected since it emerges from the intrashell multiple scattering within the first carbon shell (Peak 2). Such clear distinction in the intensity profiles for Peak " 4 "sampled prior to ignition, with Peak 4 sampled just after ignition, and after milling for $75 \mathrm{~h}$ supports an argument suggesting that the TiC that are contained in the products that are sampled prior to ignition may nucleate 
with high degree of off-stoichiometry as compared to the latter stages. A simple EELS chemical quantitative analysis using the quantification routines and scattering cross sections built into the DigitalMicrograph software was found to indicate atomic composition of $\mathrm{TiC}_{0.53}$ for the TiC formed prior to ignition, while that of the $\mathrm{TiC}$ formed just after ignition was obtained to be $\mathrm{TiC}_{0.62}$. After milling for $75 \mathrm{~h}$, the chemical analysis of the products shows increasing evolution of TiC towards stoichiometry.

A result of note is the increase in core-level energy loss region between the $L_{3}$ and $L_{2}$ bands at the Ti L-edge for products sampled prior to and after ignition. Prior to ignition, the energy region appears smaller while after ignition, such region increases to higher energy loss (Fig. $10(d))$. Such a shift is probably due to enhancement of energy shake-up that may occur in the final states of the Ti-edge. An example of this is clearly seen in the loss of intensity for peaks “3” and "7”, for the TiC C K-edge structure obtained from some selected EELS regions. The result implies that those TiC ELNES of lower peak intensities may contain a significant Ti$3 d$ character and $\mathrm{Ti}$ _ Ti bonds. Such attributes are readily displayed by off-stoichiometric compounds where the presence of the non-metal atoms (C) does not readily create a strong influence in the lattice of the $\mathrm{Ti} \_\mathrm{C}$ bonds [68]. In any case, further analyses is required to determine the nature and the core-level energy associated with such shake-up features in $\mathrm{TiC}$ induced during milling.

\section{Conclusions}

Reaction sequences and mechanisms during mechanically induced self-propagating reaction synthesis of TiC from elemental titanium and carbon (graphite) have been explored using Raman spectroscopy and XPS and, and additional FESEM, HRTEM and STEM-EELS. From the present work it can be concluded that:

(1) During early stages of milling a pre-reaction incubation period is associated with sequence of formation of lamellar $\mathrm{Ti}$, quasi spherical nanographitic particles, heterogeneous mixtures of $\mathrm{Ti}$ and $\mathrm{C}$, clumping of graphite around the heavily deformed $\mathrm{Ti}$ particles, induced strains and possible carbon dissolution into the Ti grains.

(2) With increased milling time before ignition, nano-TiC crystals are formed through a reaction that is likely deformation-induced, between the heavily deformed $\mathrm{Ti}$ and amorphous C. This reaction is believed to be promoted by both increases in the local temperature and pressure of the powders, and accumulation of deformation defects (dislocations, vacancies, twinning and stacking faults) in the unreacted Ti.

(3) The chemistries of the products formed before ignition were revealed by Raman spectroscopy to include off-stoichiometric $\mathrm{TiC}_{1-x}$ particles, with an evolution towards stoichiometric TiC after extended milling times.

(4) Combined FESEM and TEM techniques reveal that immediately after ignition, there is rapid nucleation of new $\mathrm{TiC}$ crystals and to simultaneous growth of pre-existing TiC. The growth of the $\mathrm{TiC}$ crystals is manifest by the formation of stacks of $\mathrm{TiC}$ multi-layers with regions of irregular, perfect, imperfect hexagonal and octahedral units of TiC grains.

(5) XPS revealed some surface oxidation of the reacting ingredients ( $\mathrm{Ti}, \mathrm{C}$ ) as well as some of the reacted product (TiC). Minor fractions of oxidized $\mathrm{TiC}_{\mathrm{x}} \mathrm{O}_{\mathrm{y}}$ are attributed to both the presence of oxygen in the starting materials and/or surface oxidation prior to analysis. 
(6) The high spatially-resolved EELS combined with STEM revealed the chemical environment of the milled powders to be inhomogeneous with distinct changes in the edgestructures of $\mathrm{TiC}$ with selected regions and milling times.

(7) Given the dual nature of the MSR reaction product, and its morphology, MSR is believed to occur via a mechanism involving growth of pre-existing nano-TiC, and high temperature nucleation and growth of new TiC particles with local melting of unreacted Ti resulting in a liquid phase sintered reaction product.

Dr. J.E. Oghenevweta is a full-time Senior Lecturer at the Department of Metallurgical and Materials Engineering, Ahmadu Bello University, Nigeria. He holds a $\mathrm{PhD}$ degree from the University of Wollongong, Australia and he is currently undertaking extensive research at the Department of Materials Engineering, Faculty of Engineering and Information Sciences, University of Wollongong, Australia.

Dr. D. Wexler is a full-time Senior Research Fellow at the Department of Materials Engineering, Faculty of Engineering and Information Sciences, University of Wollongong, Australia.

Professor A. Calka is a full-time Professor of Materials Engineering at the Department of Materials Engineering, Faculty of Engineering and Information Sciences, University of Wollongong, Australia.

\section{Acknowledgements}

We acknowledge the Australian Research Council (ARC) for grants; LE120100104, LE0237478, and LE0882613; for use of equipment and facilities located at the UOW Electron Microscopy Centre (EMC) and UOW node of the Australian National Nanofabrication Facility (ANNF). We would like to thank Drs. Gilberto CasillasGarcia and D.R.G. Mitchell for their professional EELS editing and interpretation.

\section{References}

[1] G.A. Dorofeev, V.I. Ladjanov, A.N. Lubnin, F.Z. Gilmutdinov, E. V Kuzminykh, S.M. Ivanov, Initial Stage of Mechanochemical Synthesis in the Ti - C Exothermic System, Bull. Russ. Acad. Sci. Phys. 75 (2011) 1518-1525.

[2] J.E. Oghenevweta, D. Wexler, A. Calka, Early stages of phase formation before the ignition peak during mechanically induced self-propagating reactions (MSRs) of titanium and graphite, Scr. Mater. 122 (2016).

[3] L. Takacs, Self-sustaining reactions induced by ball milling, Prog. Mater. Sci. 47 (2002) 355-414.

[4] F. Delogu, L. Takacs, Mechanochemistry of Ti-C powder mixtures, Acta Mater. 80 (2014) 435-444.

[5] L. Takacs, Ball milling-induced combustion in powder mixtures containing titanium, zirconium, or hafnium, J. Solid State Chem. 125 (1996) 75-84.

[6] F. Delogu, Activation of self-sustaining high-temperature reactions by mechanical processing of Ti-C powder mixtures, Scr. Mater. 69 (2013) 223-226.

[7] N.Q. Wu, S. Lin, J.M. Wu, Z.Z. Li, Mechanosynthesis mechanism of TiC powders, Mater. Sci. Technol. 14 (1998).

[8] B.H. Lohse, A. Calka, D. Wexler, Synthesis of TiC by controlled ball milling of titanium and carbon, J. Mater. Sci. 42 (2007) 669-675. 
[9] B.H. Lohse, A. Calka, D. Wexler, Effect of starting composition on the synthesis of nanocrystalline TiC during milling of titanium and carbon, J. Alloys Compd. 394 (2005) 148-151.

[10] Z.G. Liu, J.T. Guo, L.L. Ye, G.S. Li, Z.Q. Hu, Formation mechanism of TiC by mechanical alloying, Appl. Phys. Lett. 65 (1994) 2666-2668. doi:10.1063/1.112596.

[11] N.Q. Wu, G. Wang, J.M. Wu, Z.Z. Li, M.Y. Yuad, Investigation of TiC formation during Ball-milling of elemental titanium and carbon, 15 (1997) 289-293.

[12] M.A. Avilés, E. Chicardi, J.M. Cõrdoba, M.J. Sayagués, F.J. Gotor, In situ synthesis of ceramic composite materials in the Ti-B-C-N system by a mechanically induced selfsustaining reaction, J. Am. Ceram. Soc. 95 (2012) 2133-2139.

[13] G.B. Schaffer, P.G. McCormick, Combustion synthesis by mechanical alloying, Scr. Metall. 23 (1989) 835-838.

[14] L. Takacs, Solid state reactions induced by ball milling, 111 (1998) 245-250.

[15] G.B. Schaffer, P.G. McCormick, Anomalous combustion effects during mechanical alloying, Metall. Trans. A. 22 (1991) 3019-3024.

[16] J.S. Forrester, G.B. Schaffer, The chemical kinetics of mechanical alloying, 26 (1995) 725-730.

[17] G.B. Schaffer, P.G. McCormick, On the kinetics of mechanical alloying, Metall. Trans. A. 23 (1992) 1285-1290.

[18] F. Delogu, A combined experimental and numerical approach to the kinetics of mechanically induced phase transformations, Acta Mater. 56 (2008) 905-912.

[19] F. Delogu, R. Orrù, G. Cao, A novel macrokinetic approach for mechanochemical reactions, Chem. Eng. Sci. 58 (2003) 815-821.

[20] F. Delogu, G. Cocco, Relating single-impact events to macrokinetic features in mechanically alloying processes, J. Mater. Synth. Process. 8 (2000) 271-277.

[21] D.R. Maurice, T.H. Courtney, The physics of mechanical alloying: A first report, Metall. Trans. A. 21 (1990) 289-303.

[22] T.H. Courney, Process modelling of mechanical alloying (Overview), Mater. Trans. JIM. 36 (1995) 110-122.

[23] C. Deidda, F. Delogu, F. Maglia, U. Anselmi-Tamburini, G. Cocco, Mechanical processing and self-sustaining high-temperature synthesis of TiC powders, Mater. Sci. Eng. A. 375-377 (2004) 800-803.

[24] B. Ghosh, S.K. Pradhan, Microstructure characterization of nanocrystalline TiC synthesized by mechanical alloying, Mater. Chem. Phys. 120 (2010) 537-545.

[25] B.H. Lohse, A. Calka, D. Wexler, Raman spectroscopy sheds new light on TiC formation during the controlled milling of titanium and carbon, J. Alloys Compd. 434435 (2007) 405-409.

[26] J.E. Oghenevweta, D. Wexler, A. Calka, Sequence of phase evolution during mechanically induced self-propagating reaction synthesis of $\mathrm{TiB}$ and $\mathrm{TiB} 2 \mathrm{via}$ magnetically controlled ball milling of titanium and boron powders, J. Alloys Compd. 701 (2017) 380-391.

[27] H.M. Rietveld, Line profiles of neutron powder-diffraction peaks for structure refinement, Acta Crystallogr. 22 (1967) 151-152.

[28] R.A. Young, D.B. Wiles, Profile shape functions in Rietveld refinements, J. Appl. Crystallogr. 15 (1982) 430-438.

[29] H. Rietveld, A profile refinement method for nuclear and magnetic structures, J. Appl. Crystallogr. 2 (1969) 65-71.

[30] L. Lutterotti, Quantitative Rietveld analysis in batch mode with Maud, (2011).

[31] D.R.G. Mitchell, A suite of software tools with which to process spectra and Spectrum Images, version:20160903, v4.0., (2016). 
[32] C. Deidda, S. Doppiu, M. Monagheddu, G. Cocco, A direct view of the self combustion behaviour of TiC system under milling, J. Metastable Nanocrystalline Mater. 15-16 (2003) 215-220.

[33] K.B. Modi, S.N. Dolia, P.U. Sharma, Effect of mechanical milling induced strain and particle size reduction on some physical properties of polycrystalline yttrium iron garnet, Indian J. Phys. 89 (2015) 425-436.

[34] P. Ayyub, V.R. Palkar, S. Chattopadhyay, M. Multani, Effect of crystal size reduction on lattice symmetry and cooperative properties, Phys. Rev. B. 51 (1995) 6135.

[35] S.D. Shenoy, P.A. Joy, M.R. Anantharaman, Effect of mechanical milling on the structural, magnetic and dielectric properties of coprecipitated ultrafine zinc ferrite, J. Magn. Magn. Mater. 269 (2004) 217-226.

[36] M. V. Klein, J.A. Holy, W.S. Williams, Raman scattering induced by carbon vacancies in TiCx, Phys. Rev. B. 17 (1978) 1546-1556. doi:10.1103/PhysRevB.17.1546.

[37] M. Amer, M.W. Barsoum, The Raman spectrum of Ti3SiC2., J. Appl. Phys. 84 (1998) 5817. doi:10.1063/1.368849.

[38] and C.W.B. Ferraro, J.R., K. Nakamoto, Introductory Raman Spectroscopy., second, USA: Academic Press, 2003.

[39] P.V. Huong, a. L. Verma, J.-P. Chaminade, L. Nganga, J.-C. Frison, Characterization of materials by micro-Raman spectroscopy, Mater. Sci. Eng. B. 5 (1990) 255-260.

[40] N. Oláh, M. Veres, A. Sulyok, M. Menyhárd, J. Gubicza, K. Balázsi, Examination of nanocrystalline TiC/amorphous C deposited thin films, J. Eur. Ceram. Soc. 34 (2014) 3421-3425.

[41] S. Pellegrino, L. Thomé, A. Debelle, S. Miro, P. Trocellier, Radiation effects in carbides: TiC and $\mathrm{ZrC}$ versus SiC, Nucl. Instruments Methods Phys. Res. Sect. B Beam Interact. with Mater. Atoms. 327 (2014) 103-107.

[42] Y. Kawashima, G. Katagiri, Fundamentals, overtones, and combinations in the Raman spectrum of graphite, Phys. Rev. B. 52 (1995) 10053.

[43] P. Unifantowicz, S. Vaucher, M. Lewandowska, K.J. Kurzydłowski, Structural changes of silicon upon high-energy milling investigated by Raman spectroscopy, J. Phys. Condens. Matter. 20 (2008) 25205.

[44] M.S. Song, B. Huang, Y.Q. Huo, S.G. Zhang, M.X. Zhang, Q.D. Hu, J.G. Li, Growth of TiC octahedron obtained by self-propagating reaction, J. Cryst. Growth. 311 (2009) 378-382.

[45] Z. Zhao, T. Diemant, D. Rosenthal, K. Christmann, J. Bansmann, H. Rauscher, R.J. Behm, Au/TiO 2/Ru (0001) model catalysts and their interaction with CO, Surf. Sci. 600 (2006) 4992-5003.

[46] Z. Xin, M. Lei, W. Jian-Gang, Z. Hui-Min, Investigation on ultrathin titanium oxide films synthesized by surface sol-gel method, Optik (Stuttg). 127 (2016) 2780-2783.

[47] A. Felten, I. Suarez-Martinez, X. Ke, G. Van Tendeloo, J. Ghijsen, J.J. Pireaux, W. Drube, C. Bittencourt, C.P. Ewels, The role of oxygen at the interface between titanium and carbon nanotubes, Chem Phys Chem. 10 (2009) 1799-1804.

[48] G. Li, L.F. Xia, Structural characterization of TiC x films prepared by plasma based ion implantation, Thin Solid Films. 396 (2001) 16-22.

[49] E.R. Parra, P. Jose, A. Arango, V.J. Benavides, XPS structure analysis of TiN / TiC bilayers produced by pulsed vacuum arc discharge, Dyna 163 (2010) 64-74.

[50] M. Magnuson, E. Lewin, L. Hultman, U. Jansson, Electronic structure and chemical bonding of nanocrystalline-TiC/amorphous-C nanocomposites, Phys. Rev. B. 80 (2009) 235108.

[51] R. Alexandrescu, E. Borsella, S. Botti, M. Cesile, S. Martelli, R. Giorgi, S. Turtu, G. Zappa, Synthesis of $\mathrm{TiC}$ and $\mathrm{SiC} / \mathrm{TiC}$ nanocrystalline powders by gas-phase laser- 
induced reaction, J. Mater. Sci. 32 (1997) 5629-5635.

[52] J.Y. Huang, HRTEM and EELS studies of defects structure and amorphous-like graphite induced by ball-milling, Acta Mater. 47 (1999) 1801-1808.

[53] A. Scott, R. Brydson, M. MacKenzie, A. Craven, Theoretical investigation of the ELNES of transition metal carbides for the extraction of structural and bonding information, Phys. Rev. B. 63 (2001) 1-13.

[54] A.J. Craven, The electron energy-loss near-edge structure (ELNES) on the NK-edges from the transition metal mononitrides with the rock-salt structure and its comparison with that on the CK-edges from the corresponding transition metal monocarbides, J. Microsc. 180 (1995) 250-262.

[55] A.J. Craven, L.A.J. Garvie, Electron energy loss near edge structure (ELNES) on the carbon K-edge in transition metal carbides with the rock salt structure, Microsc. Microanal. Microstruct. 6 (1995) 89-98.

[56] J. Pflüger, J. Fink, G. Crecelius, K.P. Bohnen, H. Winter, Electronic structure of unoccupied states of TiC, TiN, and VN by electron-energy-loss-spectroscopy, Solid State Commun. 44 (1982) 489-492.

[57] Z. Feng, S. Löffler, F. Eder, D. Su, J.C. Meyer, P. Schattschneider, Combined study of the ground and unoccupied electronic states of graphite by electron energy-loss spectroscopy, J. Appl. Phys. 114 (2013) 183716.

[58] E. Stoyanov, F. Langenhorst, G. Steinle-Neumann, The effect of valence state and site geometry on Ti L3, 2 and OK electron energy-loss spectra of TixOy phases, Am. Mineral. 92 (2007) 577-586.

[59] B.H. Lohse, A. Calka, D. Wexler, Raman spectroscopy as a tool to study TiC formation during controlled ball milling, J. Appl. Phys. 97 (2005).

[60] A. Tonejc, C. Kosanović, M. Stubićar, A.M. Tonejc, B. Subotić, I. Smit, Equivalence of ball milling and thermal treatment for phase transitions in the $\mathrm{Al}_{2} \mathrm{O}_{3}$ system, $\mathrm{J}$. Alloys Compd. 204 (1994) L1-L3.

[61] R. Weichert, K. Schönert, On the temperature rise at the tip of a fast running crack, J. Mech. Phys. Solids. 22 (1974) 127-133.

[62] A. Tonejc, A.M. Tonejc, D. Bagović, C. Kosanović, Comparison of the transformation sequence from $\gamma$-AlOOH (boehmite) to $\alpha-\mathrm{Al} 2 \mathrm{O} 3$ (corundum) induced by heating and by ball milling, Mater. Sci. Eng. A. 181 (1994) 1227-1231.

[63] J.Y. Huang, Y.K. Wu, H.Q. Ye, Deformation structures in ball milled copper, Acta Mater. 44 (1996) 1211-1221.

[64] C. Suryanarayana, Mechanical alloying and milling, Prog. Mater. Sci. 46 (2001) 1184.

[65] W. Guo, J. Yao, E.A. Jägle, P.-P. Choi, M. Herbig, J.M. Schneider, D. Raabe, Deformation induced alloying in crystalline-metallic glass nano-composites, Mater. Sci. Eng. A. 628 (2015) 269-280.

[66] M.X. Zhang, Q.D. Hu, Y.Q. Huo, B. Huang, J.G. Li, Formation and growth mechanism of TiC terraces during self-propagating high-temperature synthesis from a Fe $\square$ Ti $\square$ C system, J. Cryst Growth. 355 (2012) $140-144$.

[67] P. Hartman, Crystal growth: an introduction, North Holland, 1973.

[68] S. V. Didziulis, J.R. Lince, T.B. Stewart, E.A. Eklund, Photoelectron spectroscopic studies of the electronic structure and bonding in TiC and TiN, Inorg. Chem. 33 (1994) 1979-1991. 